\title{
Autoridades Políticas Jóvenes en Perú. UN ANÁLISIS SOBRE LAS PERCEPCIONES QUE TIENEN DE LA POLÍTICA INSTITUCIONAL ${ }^{1}$
}

\author{
FRANCO EVANS MORALES ${ }^{2}$
}

\begin{abstract}
RESUMEN
En el presente artículo se describen las percepciones que las autoridades políticas jóvenes electas en el Perú durante el período 2015 a 2018 tienen de la política institucional. Para ello se consideraron variables como educación, empleo, participación juvenil, trayectorias políticas, así como las percepciones que las autoridades jóvenes tienen sobre la democracia, la política y las condiciones juveniles. Se aplicaron 172 encuestas a estos actores en el VI Encuentro Nacional de Autoridades Políticas Jóvenes, realizado en la ciudad de Lima. Las percepciones se caracterizan por rastrear condiciones juveniles diferenciadas en lo educativo y laboral, así como significados que asocian a la democracia y la política con la discusión de lo público y el bien común.
\end{abstract}

PALABRAS CLAVES: EDUCACIÓN, PARTICIPACIÓN, DEMOCRACIA

\footnotetext{
${ }^{1}$ Investigación dedicada a las memorias de Rufino Evans y de José Montalvo, ex Secretario Nacional de la Juventud de Perú.

2 Licenciado en Sociología por la Universidad Nacional Mayor de San Marcos (UNMSM) de Perú, estudiante de Maestría en Sociología por la UNMSM. Correo electrónico: franco.evans92@gmail.com
} 


\title{
Autoridades POLÍticas JOVEnS NO PERU. UMA ANÁLISE SOBRE SUAS PERCEPÇÕES DA POLÍTICA INSTITUCIONAL
}

\begin{abstract}
RESUMO
Este artigo descreve as percepções que as autoridades políticas jovens eleitas no Peru entre 2015 e 2018 têm da política institucional. Para isso, foram consideradas variáveis como a educação, o emprego, a participação juvenil, as trajetórias políticas, bem como as percepções que as autoridades jovens têm sobre a democracia, a política e as condições juvenis. Foram administradas 172 pesquisas a estes atores no VI Encontro Nacional de Autoridades Políticas Jovens, realizado na cidade de Lima. As percepções se caracterizam por seguir condições juvenis diferenciadas na educação e no trabalho, bem como significados que associam a democracia e a política à discussão do público e do bem comum.
\end{abstract}

PALAVRAS-CHAVE: EDUCAÇÃO, PARTICIPAÇÃO, DEMOCRACIA

\section{Young POLITICAL AUTHORITIES IN PERU. AN ANALYSIS ON THEIR PERCEPTIONS ABOUT INSTITUTIONAL POLICY}

\begin{abstract}
This article describes the perceptions that young political authorities elected in Peru from 2015 to 2018 have about institutional policy. Variables such as education, employment, youth participation, political trajectories, as well as the perceptions young authorities have about democracy, politics and youth conditions have been considered for such purpose. 172 surveys were taken to these actors at the VI National Meeting of Young Political Authorities held in the city of Lima. The perceptions are characterized by tracing differentiated youth conditions in education and work-related matters, as well as those meanings associating democracy and politics with the discussion about the public matter and common good.
\end{abstract}

KEYWORDS: EDUCATION, PARTICIPATION, DEMOCRACY 


\section{INTRODUCCIÓN}

La categoría analítica de juventud como construcción social, histórica, cultural y relacional está vigente en los debates y abordajes de las ciencias sociales y políticas públicas en las sociedades contemporáneas. Si bien a lo largo de la historia las y los jóvenes han sido sujetos de distintas definiciones púberes en las sociedades primitivas, efebos en los Estados de las sociedades antiguas, mozos en las sociedades campesinas preindustriales, muchachos a inicios de la industrialización, hasta llegar a la denominación de jóvenes en las sociedades posindustriales (Feixa, 1999)_, es recién en la sociedad moderna que la categoría de juventud se transformó en un tema de interés social y político en varios países del hemisferio occidental, además de una materia de teorización académica (Nureña, 2015; Souto, 2007; Dávila, 2004).

La juventud no es solo una categoría etaria que transcurre con el paso del tiempo, también es una condición social diferenciada con cualidades específicas que se expresan de diferentes formas según las condiciones sociohistóricas en que se desenvuelven los individuos (Dávila, 2004), además las y los jóvenes se encuentran inmersos en redes y estructuras de poder (Valenzuela, 2005). Es decir, según el espacio y el tiempo en el que transcurren sus vidas, presentan características particulares, poseen necesidades y demandas específicas y buscan satisfacerlas a través de estrategias particulares; una de ellas es a través de la participación política.

Sobre este vínculo entre política y juventudes, aunque se pueda rastrear la presencia de activismo juvenil en el campo de lo político a partir de inicios de la época republicana en el Perú, es a comienzos del siglo XX que el proceso 


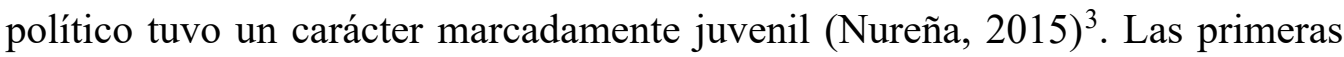
manifestaciones juveniles se dan con los movimientos de apoyo a la reforma universitaria de 1919, en un contexto de movilizaciones estudiantiles y obreras donde las condiciones económicas, laborales y sociales produjeron un marcado descontento en la sociedad peruana; es allí donde comienzan a surgir personajes jóvenes importantes como Víctor Raúl Haya de la Torre y José Carlos Mariátegui, quienes dan comienzo a las dos tradiciones políticas que marcarían el rumbo político del Perú a lo largo del siglo ${ }^{4}$.

A partir de la segunda mitad del siglo XX en adelante, en un contexto de aguda transformación de la sociedad peruana, caracterizada por las migraciones masivas, la expansión del sistema educativo, el incremento de la oferta y demanda de estudios universitarios, la vida política adquiere un visible rostro juvenil. Se aprecia con mayor intensidad la presencia de jóvenes organizados en universidades públicas, sindicatos laborales y partidos políticos que se constituyen en actores disconformes con el sistema político nacional. Lo ocurrido en el Perú a partir de 1980 en el contexto de la guerra interna y la violencia política es el caso más extremo de radicalización política liderada por el Partido Comunista-Sendero Luminoso, que adhirió a un numeroso grupo de jóvenes que demandaban un proyecto de igualdad y justicia social. Se han reportado, a través de la Comisión de la Verdad y Reconciliación (CVR), las catastróficas consecuencias que trajo el accionar de esta agrupación política, desde grandes pérdidas humanas hasta la respuesta del Estado en políticas de reparación civil, así como la crisis institucional de los partidos políticos y su impacto negativo en

\footnotetext{
${ }^{3}$ Sin embargo, como sostiene Tanaka (1995), hasta antes de la década de los setenta la temática juvenil como campo específico de conocimiento no existía, mucho menos los actores juveniles propiamente dichos, ya que se encontraban inmersos dentro de las categorías de clase propias de las sociedades de masas y los procesos de modernización.

${ }^{4}$ Un par de años más tarde, a mediados de la década de los cuarenta, el joven Fernando Belaúnde Terry ingresa al Parlamento como diputado y se vincula con otros jóvenes para conformar el Frente Nacional de Juventudes Democráticas (FNJD).
} 
la participación política de las juventudes del país.

Durante la década de los noventa las y los jóvenes enfrentaron un fuerte proceso de estigmatización social, ya que bastaba mostrar alguna simpatía o participación en grupos políticos de izquierda para ser calificados como terroristas. Precisamente, Degregori (2014) calificó a los años noventa como la década de la antipolítica, debido a que fue un período de persistente incertidumbre política, además se hizo evidente la crisis de representación de los partidos políticos tradicionales como espacios de intermediación por excelencia entre la sociedad y el Estado (Lynch, 1999). Esta situación fue uno de los factores para el surgimiento de la figura del outsider como aquel político(a) independiente que reemplaza la intermediación de instituciones democráticas y públicas por vínculos personalistas para acercarse a la población bajo la figura del líder. A lo largo de los años esta fragilidad del sistema político se ha institucionalizado a medida que las sociedades se insertan en lógicas como la globalización y el mercado neoliberal, pues los partidos políticos ofertan candidaturas políticas al mejor postor, constituyéndose en vientres de alquiler donde las carreras políticas se alquilan sobre la base de intereses económicos durante períodos electorales.

Todos estos factores tuvieron impacto en el escenario político peruano durante los años noventa, ocasionando que el protagonismo político de las juventudes se redujera hasta casi extinguirse. El siglo XXI inicia con una percepción generalizada de una aparente apatía juvenil en la política, debido a los escasos niveles de participación y de una supuesta adherencia total de las juventudes hacia las lógicas de consumo mercantil (Rodríguez, 2013). Dentro de la academia también empezaron a surgir estudios que indagan la participación política de las juventudes y su baja militancia en los partidos políticos, se comenzaron a realizar abordajes que resaltaban las actitudes apolíticas o desinteresadas de la política que tenían las y los jóvenes (Edwards, 2007; Fernández, 2003; Kimberlee, 2002). Sin embargo el actual escenario mundial presenta nuevas formas de expresión política juvenil como los movimientos de 
los indignados en España, los pingüinos en Chile, el movimiento Yo soy 132 en México o las movilizaciones juveniles de organización territorial contra el régimen laboral juvenil en el Perú (Fernández Maldonado, 2015), que dan cuenta que no son las y los jóvenes quienes se despolitizan, sino más bien aplican formas de expresión política reconfiguradas (Banaji, 2008; Serna, 1998; Tereshchenko, 2010).

En términos concretos, lo que se da no es el distanciamiento de las juventudes de lo político; por el contrario, es la desafección hacia las instituciones y prácticas que conforman los sistemas políticos (falta de renovación generacional en los partidos políticos, financiamiento ilícito hacia agrupaciones políticas, sistemas de corrupción, colapso de la democracia representativa), proceso que Benedicto (2013) llama desinstitucionalización o como lo afirma Valenzuela (2012), las y los jóvenes pueden ser apartidarios pero no necesariamente apolíticos.

Como una medida para enfrentar esta situación, y ante un acelerado crecimiento de la población juvenil, que se encontraba subrepresentada políticamente en el ámbito local, es que en el año 2006 surge una iniciativa del Estado peruano para promover la participación activa de las y los jóvenes en contiendas electorales, y en consecuencia, en los gobiernos locales. Esta iniciativa es la promulgación de la Ley N. ${ }^{\circ} 28.869$, denominada Ley del Concejal Joven y más conocida como la cuota joven, que modifica el artículo 10 de la Ley de Elecciones Municipales, estableciendo que los partidos políticos deben incorporar un mínimo de $20 \%$ de jóvenes menores de 29 años en sus listas de candidatos a regidores provinciales y municipales ${ }^{5}$ (ONPE, 2008). En las

\footnotetext{
${ }^{5}$ A diferencia de la cuota de género, que fue una conquista de lucha del movimiento femenino, la cuota joven se implementó en el Perú como una política pública por iniciativa del Estado. Para Baldeón (2015), la consecuencia de que la cuota joven no sea parte de una reivindicación aclamada por el movimiento juvenil es que su aplicación se limita al ámbito subnacional (municipal y regional) y todavía no tiene alcance nacional.
} 
Elecciones Regionales y Municipales 2014 fueron elegidas 1.612 autoridades jóvenes, cifra que representó el 12,9\% del total de autoridades electas en el Perú (Jurado Nacional de Elecciones, 2015).

Desde la promulgación de la ley, existe una presencia cada vez mayor de las y los jóvenes como candidatos en las listas electorales, lo que da cuenta del interés de un segmento de la población juvenil por participar en la política institucional; sin embargo, esto no ha garantizado necesariamente una mayor presencia en el campo de la representatividad. Algunos de los factores que podrían afectar el desarrollo efectivo de la representación política juvenil se basan en la limitada economía personal y familiar de las y los jóvenes para financiar campañas políticas, falta de experiencia política, la asignación gratuita de estereotipos y prejuicios dentro de sus mismas organizaciones políticas (Yáñez, 2001), entre otros factores.

El balance de lo producido respecto a la participación juvenil en partidos políticos y en los gobiernos locales, regionales y nacionales nos invita a pensar el fenómeno de la condición juvenil como un elemento distintivo frente al mundo adulto o a la propia estructura adultocéntrica, que intenta imponer una perspectiva hegemónica de conocimientos, saberes y arquitecturas de comportamiento en el joven, para que este sea funcional a sus intereses. Esto lo podemos observar en las lógicas clientelares que instrumentalizan a las juventudes dentro de la estructura partidaria. Así, los líderes políticos con mayor cantidad de años en la militancia tienen la posibilidad de ascender en la carrera política, porque su jerarquía partidaria es funcional a la legitimidad y el estatus con el que cuentan, mientras los más jóvenes disputan posiciones políticas para ascender en la organización, sumado a las barreras generacionales que encuentran para mantener la estructura de incentivos en la participación política juvenil.

Por ello, dado el déficit de conocimiento académico en este asunto, se 
intenta discutir la condición juvenil en política, entendida como una forma de representar a las y los jóvenes como sujetos específicos y con demandas particulares dentro de la estructura social, además ocupan posiciones históricamente diferenciadas frente al mundo adulto (Castellanos, 2011). Más aún en el campo de la política, donde existen correlaciones de fuerza entre los actores con plataformas programáticas heterogéneas, es importante comenzar a rastrear estas narrativas y tramas juveniles desde la política institucional y el ejercicio de la representatividad política en los gobiernos locales, regionales y nacionales en el Perú. La condición juvenil de las autoridades políticas brinda un panorama para potenciar la conciencia crítica de la realidad política en el país, construir procesos políticos hacia una horizonte alternativo de gestión pública alejado de las estructuras tradicionales del adultocentrismo. El aporte de la investigación está en posicionar la agenda juvenil desde las propias voces, opiniones y percepciones de sus protagonistas en la política institucional, así como potenciar su accionar como actores estratégicos para el desarrollo en la transformación de su propia imagen y el significado que tienen de la política como elemento para la distribución del poder y la gestión en el ámbito público.

\section{Metodología}

Este es un estudio de carácter exploratorio, lo que significa que no pretende brindar resultados definitivos ni generales sobre el comportamiento político y las percepciones que las autoridades jóvenes tienen sobre fenómenos como la política, la democracia, la participación y la condición juvenil. Por el contrario, se busca construir aproximaciones que ayuden a comprender a las juventudes y su participación en los asuntos públicos, así tener lecturas iniciales sobre las opiniones y representaciones que tienen sobre la política institucional.

Las autoridades políticas jóvenes encuestadas fueron identificadas a partir de un muestreo no probabilístico. Dicha muestra fue escogida en el VI Encuentro 
Nacional de Autoridades Políticas Jóvenes, organizado por la Secretaría Nacional de la Juventud (SENAJU) en el mes de marzo del 2015. Este estudio no puede considerarse representativo del universo de autoridades juveniles a nivel nacional porque aborda a autoridades jóvenes reunidas en un evento específico en el que participaron solo los asistentes. La heterogeneidad de la muestra puede acercarnos de alguna manera a las percepciones que las autoridades juveniles de todo el país tienen sobre diversos elementos de la política institucional. Decimos heterogeneidad porque participaron en la encuesta varias autoridades jóvenes de ambos sexos, de diversas edades, procedentes de todas las regiones del país, con diferentes cargos políticos y algunas otras características que dan cuenta de la diversidad de la muestra.

Se aplicaron encuestas a jóvenes de diferentes partes del Perú que fueron elegidas y elegidos como autoridades políticas en las Elecciones Regionales y Municipales del año 2014. Las y los jóvenes fueron encuestados en dicho encuentro ${ }^{6}$.

El universo de autoridades políticas jóvenes en el país fue de 1.612 para el período 2015-2018, a dicho encuentro asistieron 225 autoridades jóvenes, de las cuales 125 eran mujeres y 100 varones. Allí estuvieron presentes 1 vicegobernador, 19 consejeros regionales, 63 regidores provinciales, 1 alcalde y 141 regidores distritales. Se aplicaron un total de 172 encuestas.

Se diseñó un cuestionario de 52 preguntas; para fines de este artículo solo fueron seleccionados los siguientes ítems: características educativas y laborales, para conocer su situación en los estudios superiores y técnicos así como su condición laboral; participación en espacios organizados, para tener una aproximación a su experiencia en organizaciones y asociaciones de base; percepciones sobre la democracia y la política, para explorar el significado que

${ }^{6}$ Agradezco a la antropóloga Cecilia Caparachín Puente por facilitarme los resultados de las encuestas procesadas. 
se les otorga a estos dos elementos como ejercicio de la condición ciudadana; condición juvenil y representatividad, busca indagar las características sociopolíticas que permiten reconocer a una autoridad política joven.

Previo a la aplicación de la encuesta en el Encuentro, el instrumento fue sometido a un piloteo en activistas políticos juveniles entre 18 a 29 años, integrantes de organizaciones inscritas en el Registro de Organizaciones Juveniles de SENAJU, con el objetivo de ajustar y validar las variables en cuestión. Respecto al protocolo ético, se comunicó a las y los informantes que sus datos de identidad no serían expuestos de forma pública, esto para evitar posibles conflictos de intereses debido a las posiciones políticas de diversos actores e instituciones con quienes interactúan, motivo por el cual la confidencialidad tuvo un papel trascendental y exclusivo para fines del estudio. Además, a cada autoridad joven encuestada se le explicaron los objetivos de la investigación.

\section{CARACTERÍSTICAS EDUCATIVAS Y LABORALES DE}

\section{Las Autoridades políticas Jóvenes en el Perú}

La mayoría de las autoridades políticas jóvenes encuestadas pertenece al género femenino $(60,5 \%)$; la participación mayoritaria de las mujeres en la encuesta es un reflejo de lo que sucede en el universo político de autoridades jóvenes en el Perú, donde la mayoría son mujeres ${ }^{7}$. En cuanto a la distribución por cargos de las y los encuestados, el 64,5\% son regidores distritales, 28,5\% son regidores provinciales y $7 \%$ son consejeros regionales. En todos los casos existen mayores porcentajes de participación femenina, más o menos en iguales

\footnotetext{
${ }^{7}$ A nivel nacional, el 58,3\% de autoridades jóvenes son mujeres. Las consejeras regionales llegan al 79,1\%, las regidoras provinciales al 56,4\% y las regidoras distritales al 58,8\% (SENAJU, 2015).
} 
proporciones entre los cargos: $2,3 \%$ son consejeros regionales varones y $4,4 \%$ son mujeres; $12,8 \%$ son regidores provinciales varones y $15,7 \%$ son mujeres; mientras que el $24,4 \%$ son regidores distritales varones y $40,1 \%$ son mujeres. La presencia más numerosa de mujeres electas se da sobre todo porque en el país existe la concurrencia de cuotas, es decir, la candidatura de una mujer joven cubre a la vez dos cuotas exigidas a las agrupaciones o partidos políticos (cuota de género y cuota joven).

La reivindicación de los derechos políticos y participación de las mujeres en los espacios institucionales de gobierno local, regional y nacional se ha consolidado como una demanda constante para su incorporación en la agenda pública. De hecho, la ruta histórica para posicionar este sistema de derechos en la vida política no ha trazado un camino fácil; el horizonte para el reconocimiento ciudadano de las mujeres viene recién en el siglo XX con el fomento del voto municipal, el derecho al sufragio y la adopción de la cuota de género (Bermúdez, 2018). Sin embargo, ya para el siglo XXI el desafío está en adoptar estrategias para que los partidos políticos empiecen a superar las barreras que evitan la paridad en el ejercicio de la representación política y la gestión pública por parte de varones y mujeres. Las cuotas de género brindan aportes en materia de legalidad y aplicación de la normativa; sin embargo, son insuficientes para establecer un área de compromiso político que incluya de forma regular y sistemática a las mujeres como agentes activas que contribuyen a la promoción del desarrollo desde la representación política.

Como indica Goicochea (2020), la obtención de los derechos en representación política femenina no ha sido un producto sencillo, por el contrario, se ha caracterizado por formar parte de relaciones conflictivas marcadas por desigualdades estructurales y precariedad. Entonces, proponemos tomar la participación política de las mujeres dentro de un sistema de correlaciones de fuerza en constante tensión, es decir, por un lado lidiar con la política superestructural de la institucionalidad autoritaria (Bustos, 1997) y, por otro, con 
la dinámica interna de las agrupaciones políticas que manifiestan relaciones sociales de control, jerarquía y protagonismos de los líderes varones sobre las mujeres. Esto implica reflexionar por la propia epistemología de la política en las relaciones de género y cómo se sustenta la teoría de este conocimiento en las prácticas políticas de mujeres y hombres.

La educación representa uno de los componentes trascendentales para el desarrollo humano, así como un mecanismo de movilidad social y de empleabilidad dentro del mercado laboral. Sin embargo, en el transcurso de los últimos procesos electorales en el Perú se ha podido notar que para incursionar en política no se exige con obligatoriedad a las y los candidatos algún nivel educativo específico, por ello el reto está en indagar si las desigualdades estructurales de acceso a la educación tienen impacto en la participación de las y los jóvenes dentro de los procesos electorales y posteriormente en el ejercicio de las funciones de representación como autoridades políticas. En total, el 36,6\% de las autoridades políticas jóvenes encuestadas han completado sus estudios superiores universitarios, el $25,6 \%$ ha alcanzado estudios superiores universitarios pero incompletos y el 18,6\% ha completado estudios superiores técnicos.

Se muestra que las autoridades jóvenes en su mayoría han seguido trayectorias educativas que implican la educación superior, en contraste con los bajos porcentajes representados por aquellas y aquellos que solo culminaron la educación regular básica a nivel escolar. Llama también la atención que solo el $4,1 \%$ de las autoridades jóvenes tienen o están cursando algún posgrado, pues demanda mayores inversiones económicas, nuevos tiempos para volver a la dinámica estudiantil y la prioridad que dichos estudios tienen en el mediano y largo plazo como parte de sus proyectos de vida profesional.

Según género, son los varones quienes tienen mayor porcentaje de educación superior universitaria completa (36,8\% frente a $36,5 \%$ de las mujeres), 
por otro lado, son las mujeres quienes tienen mayor porcentaje de educación superior técnica completa (19,2\% frente a $17,6 \%$ de los varones). También se resalta que el 5,8\% de las autoridades jóvenes mujeres hayan seguido estudios de posgrado frente apenas el 1,5\% de autoridades jóvenes varones (ver gráfico 1).

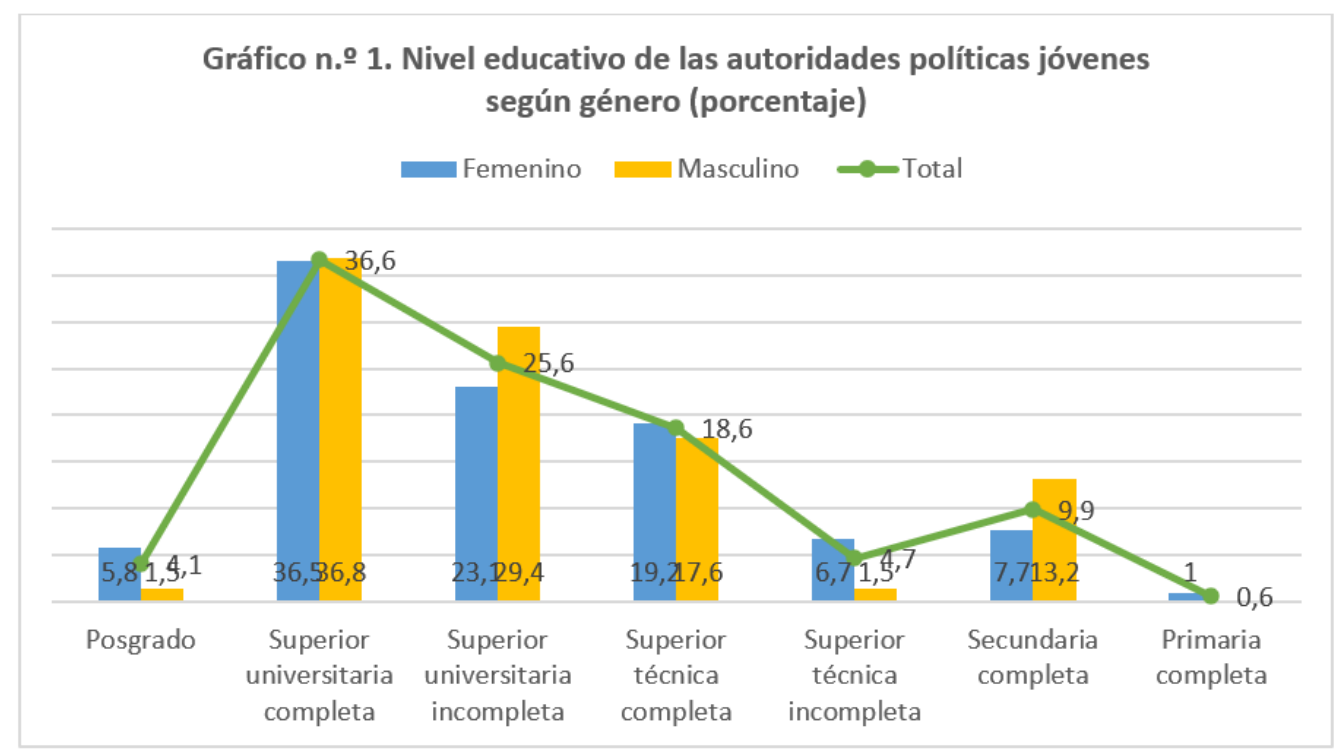

Fuente: Elaboración propia, sobre la base de encuesta a Autoridades Políticas Jóvenes 2015.

Según rubro educativo, las autoridades políticas jóvenes pertenecen en su mayoría a profesiones vinculadas a las ciencias sociales, comerciales y derecho, donde el $51,6 \%$ de regidores distritales jóvenes está formado profesionalmente en estos rubros, así como el 51\% de regidores provinciales jóvenes y en menor porcentaje los consejeros regionales, con un 41,7\%. El segundo rubro educativo con mayores porcentajes está formado por las profesiones como ingenierías, industria y construcción, donde el $25 \%$ de consejeros regionales se ha formado en estos rubros educativos, el 18,4\% fueron elegidos como regidores provinciales y el 14\% como regidores distritales. El tercer rubro está compuesto por profesiones vinculadas con la educación, donde el 25\% de consejeros regionales 
la han estudiado, así como el $10,2 \%$ de regidores provinciales y $5,4 \%$ de regidores distritales.

Las autoridades políticas jóvenes han tenido una formación profesional vinculada a las humanidades, ciencias sociales y el derecho, que se asocia con su participación en espacios políticos, en gran medida por la capacidad crítica del entorno y la sociedad que se impulsa desde estas carreras, sumado a esto se incluye el contexto político de las universidades públicas donde las correlaciones de fuerzas políticas ponen en disputa el poder de los actores. Llama la atención que las carreras profesionales técnicas y que requieren de competencias más operativas como las ciencias de la ingeniería y la construcción tengan vínculo con la participación en espacios políticos, lo que puede ir en contra del imaginario común que asume que las y los profesionales de estas carreras no tienen interés en la política.

Sin embargo, independientemente si se trata de profesiones técnicas o vinculadas a las ciencias sociales, la participación política termina siendo un componente transversal al ejercicio profesional y a la propia vida personal, pues no son dos dimensiones aisladas, por el contrario, el ejercicio profesional como la incidencia y participación en los espacios políticos se complementan basados en el aporte que los conocimientos profesionales pueden brindar a las propias trayectorias políticas y viceversa, ambas dimensiones toman el valor de lo público como político. Además, el 8,2\% de regidores provinciales y el 3,2\% de regidores distritales han estudiado profesiones vinculadas a las humanidades y el arte (ver cuadro 1). 
CUADRO 1. AUTORIDADES JÓVENES CON ESTUDIOS SUPERIORES, SEGÚN RUBRO EDUCATIVO Y CARGO POLÍTICO (PORCENTAJE)

\begin{tabular}{|l|c|c|c|}
\hline Rubro educativo & $\begin{array}{c}\text { Consejeros } \\
\text { regionales }\end{array}$ & $\begin{array}{c}\text { Regidores } \\
\text { provinciales }\end{array}$ & $\begin{array}{c}\text { Regidores } \\
\text { distritales }\end{array}$ \\
\hline Educación & $\mathbf{2 5}$ & $\mathbf{1 0 , 2}$ & 5,4 \\
\hline $\begin{array}{l}\text { Humanidades y } \\
\text { arte }\end{array}$ & - & 8,2 & 3,2 \\
\hline $\begin{array}{l}\text { Ciencias sociales, } \\
\text { comerciales y } \\
\text { derecho }\end{array}$ & $\mathbf{4 1 , 7}$ & $\mathbf{5 1}$ & $\mathbf{5 1 , 6}$ \\
\hline $\begin{array}{l}\text { Ciencias } \\
\text { naturales, exactas } \\
\text { y de la } \\
\text { computación }\end{array}$ & - & 2 & 5,4 \\
\hline $\begin{array}{l}\text { Ingeniería, } \\
\text { industria y } \\
\text { construcción }\end{array}$ & $\mathbf{2 5}$ & $\mathbf{1 8 , 4}$ & $\mathbf{1 4}$ \\
\hline $\begin{array}{l}\text { Agropecuaria y } \\
\text { veterinaria }\end{array}$ & - & 2 & 4,3 \\
\hline $\begin{array}{l}\text { Ciencias de la } \\
\text { salud }\end{array}$ & - & 2 & 5,4 \\
\hline Servicios & - & 4,1 & 7,5 \\
\hline $\begin{array}{l}\text { Fuerzas armadas } \\
\text { y policiales }\end{array}$ & 8,3 & - & - \\
\hline No contesta & - & 2 & 3,2 \\
\hline Fuente: Elaboratian & & & \\
\hline
\end{tabular}

Fuente: Elaboración propia, sobre la base de encuesta a Autoridades Políticas Jóvenes 2015.

Las trayectorias juveniles dentro de la vida cotidiana no son lineales, estandarizadas y predestinadas; por el contrario, los caminos en los procesos de emancipación familiar y transición laboral son reversibles, no estandarizados y no lineales, además el diseño de esas trayectorias se sustenta en la permanente tensión entre estructura y agente. Es aquello que Casal, Merino y García (2011) expresan como el encuentro entre el contexto social del sujeto y la reproducción de este en «la acumulación de experiencias individuales vitales significativas» (p. 1157), de ahí que la oportunidad sea rastrear la construcción de las trayectorias a partir de los itinerarios y expectativas juveniles que influyen en la toma de decisiones de estos jóvenes dentro del espacio educativo y laboral. 
Las trayectorias educativas y laborales de las autoridades políticas jóvenes no son lineales, sino que muchas veces son simultáneas, precisamente por la condición juvenil diferenciada y el alargamiento de la juventud como etapa de vida presente que tiene sus propias características de desarrollo. En promedio, el 42,4\% de las autoridades políticas jóvenes se encontraba solo trabajando antes de la elección, el 36\% se encontraba estudiando y trabajando a la vez, el 17,4\% solo estudiando, mientras que el 4,1\% se dedicaba solo a las labores del hogar. Por cargo político, los mayores porcentajes se concentran en solo trabajando, donde el $58,3 \%$ de consejeros regionales realizaban esta acción, el 44,1\% eran regidores distritales y el $34,7 \%$ como regidores provinciales.

Por otra parte, el 44,9\% de regidores provinciales se encontraba trabajando y estudiando a la vez antes de las elecciones, mientras que el 33,3\% de regidores distritales estaba bajo esta condición, lo mismo para el 25\% de consejeros regionales. Menores son los porcentajes de autoridades políticas jóvenes que se encontraban solo estudiando antes de las elecciones y realizando actividades de economía doméstica no calificada. Se trata de jóvenes que han adquirido trayectorias de profesionalización en el mercado laboral a nivel universitario y técnico, y una vez egresados(as) de la educación universitaria/técnica buscan proyección a la empleabilidad (ver gráfico 2).

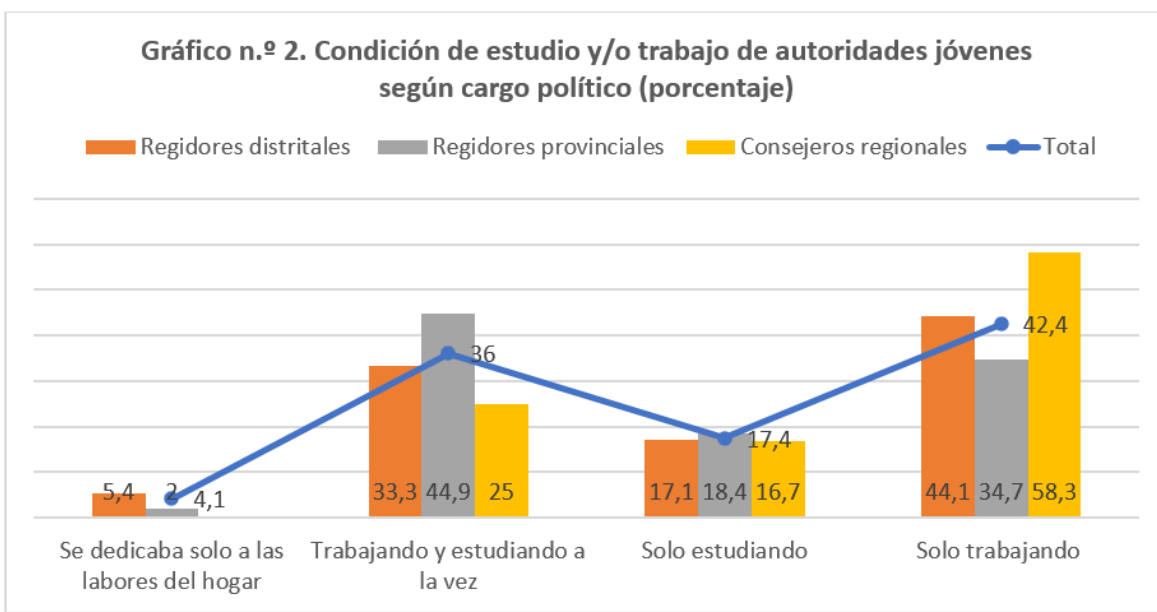

Fuente: Elaboración propia, sobre la base de encuesta a Autoridades Políticas Jóvenes 2015. 
Según condición laboral, el $53 \%$ de autoridades políticas jóvenes laboraba como trabajador/a dependiente en el sector público o privado antes de las elecciones, sea en puestos administrativos, operativos o gerenciales. El 40\% laboraba como trabajador(a) independiente, esto indica que las y los jóvenes brindaban sus competencias profesionales dentro de un mercado altamente segmentado y especializado, fuera de planilla, sin derechos laborales y sin estabilidad laboral en el mediano y largo plazo. Apenas el 5\% trabajaba como empleador/a y el $2 \%$ como trabajador/a familiar no remunerado/a, en esta última condición es posible describir que se trata de empleados/as domésticos/as o como mano de obra semicualificada dentro de unidades empresariales comúnmente llamadas MyPes (mediana y pequeñas empresas) (ver gráfico 3).

\section{Gráfico n.o 3. Autoridades jóvenes que estuvieron trabajando antes de las elecciones, según condición laboral (porcentaje)}

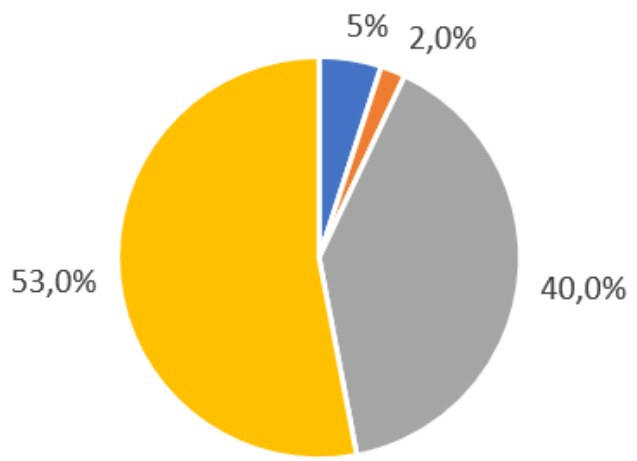

- Empleador/a

- Trabajador/a independiente
- Trabajador/a familiar no remunerado/a

- Trabajador/a dependiente

Fuente: Elaboración propia, sobre la base de encuesta a Autoridades Políticas Jóvenes 2015.

Según ocupación profesional, existen trayectorias laborales diversas en las autoridades políticas jóvenes antes de ser electos(as). El 24,4\% de los encuestados(as) trabajaba como jefe y/o empleado(a) de oficina, esto implica una 
aproximación a las labores profesionales de las y los jóvenes dentro del sector público (municipalidades, agencias municipales, burócratas en algún ministerio estatal) así como en el sector privado (personal administrativo, personal operativo, profesionales de recursos humanos o gestores). El 20\% de autoridades jóvenes trabajaba como profesional o en alguna rama de la ciencia, que podría ser desde las ciencias médicas, sociales, humanas o la ingeniería, mientras que el 15,6\% laboraba como trabajador(a) calificado(a) de servicios personales.

Existen ocupaciones identificadas con menor porcentaje, por ejemplo, apenas el 3\% de autoridades jóvenes electas trabajaban en el sector agropecuario, el 1,5\% en las Fuerzas Armadas y policiales y el 0,7\% como miembros del Poder Ejecutivo y en la dirección de alguna empresa. De esta forma, los mayores porcentajes de ocupaciones laborales se concentran en aquellas y aquellos profesionales que cumplen labores como empleados(as) burócratas de oficina en el sector público y privado realizando funciones administrativas, operativas y gerenciales, mientras que los menores porcentajes se ubican en aquellas y aquellos jóvenes profesionales con formación en ciencias agrarias y técnicos semicualificados, así como gerentes de empresas privadas que conforman una minoría electa.

Las y los jóvenes tienen que vincular distintos planos y dimensiones de su quehacer cotidiano, esto influye en la forma como se intenta brindar una imagen de coherencia en sus proyectos de vida dentro de ámbitos fragmentados como la familia, las relaciones afectivas y los espacios de sociabilidad como parte de la segmentación social de las vidas (Dávila y Ghiardo, 2018). Las juventudes tienen que enfrentar dilemas en el curso de sus vidas, la composición de sus modalidades de inserción al campo educativo y laboral se movilizan entre relaciones de integración al Estado y mercado, pero también con exclusiones y rupturas en estos espacios de la sociedad (ver gráfico 4). 


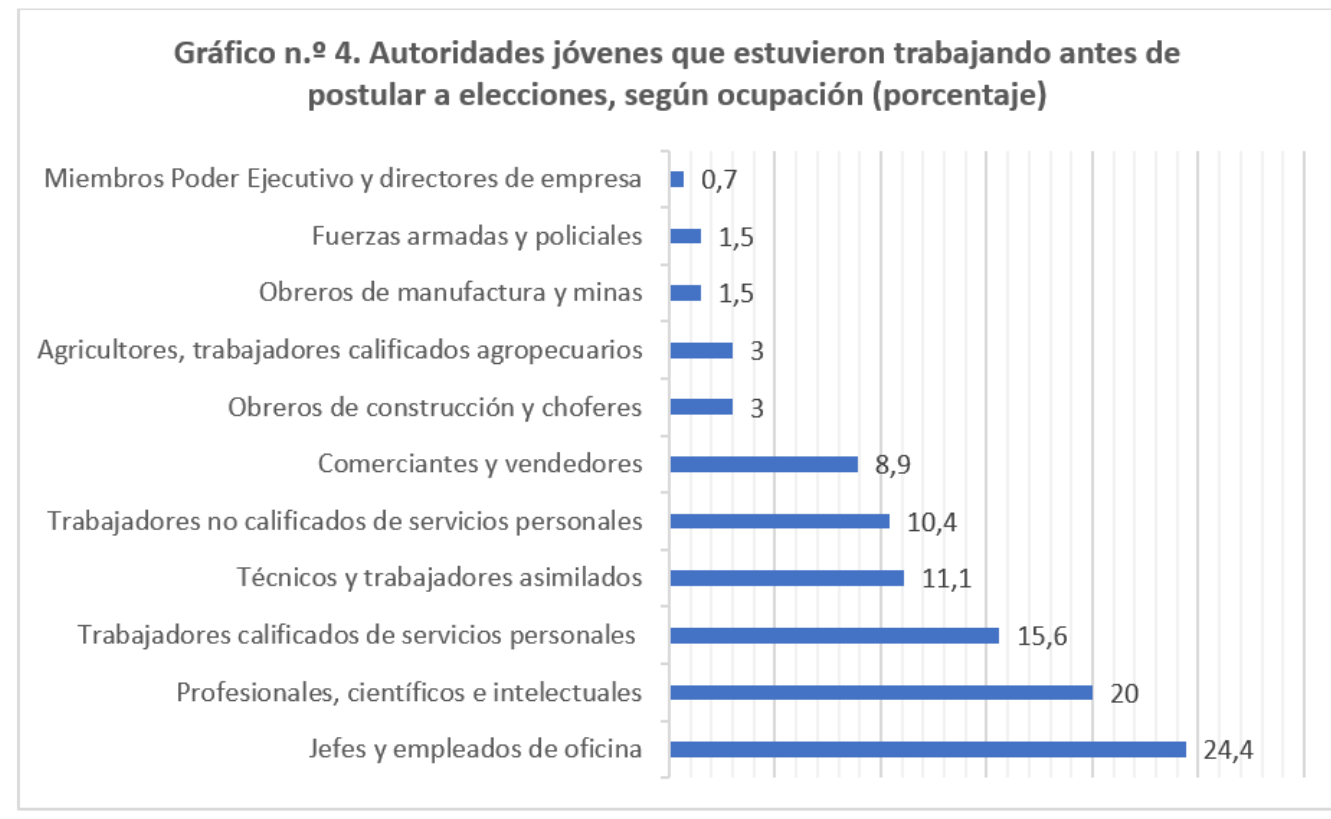

Fuente: Elaboración propia, sobre la base de encuesta a Autoridades Políticas Jóvenes 2015.

\section{PARTICIPACIÓN EN ESPACIOS ORGANIZADOS Y TRAYECTORIAS POLÍTICAS}

Las características de organización que las autoridades políticas jóvenes desarrollan como trayectorias de participación en espacios colectivos e institucionales se encuentran dentro de los partidos políticos y en el mercado electoral, es decir, ya no son los partidos políticos tradicionales y de masas con militancia estructurada y ritual ideológico los que tienen la hegemonía en la participación política juvenil. Las trayectorias políticas se han individualizado, en medio de un contexto donde el sistema de partidos políticos ha colapsado, y los vínculos partidarios suelen formarse por medio de coaliciones de políticos independientes (Levitsky y Zavaleta, 2019) solo para la contienda electoral.

Las y los jóvenes desarrollan su carrera política en un contexto de permanentes cambios sociales, políticos, económicos, culturales y tecnológicos que los incentiva a diseñar estrategias, tácticas y performances individuales para 
la militancia partidaria y la competencia electoral en las elecciones primarias internas o las nóminas de alquiler de puestos en listas presidenciales $\mathrm{y}$ parlamentarias. El asunto es que las y los candidatos para autoridades ya no demandan exclusivamente recursos logísticos, económicos y redes de contactos profesionales a los partidos políticos, muchos de estos incentivos se encuentran dispersos «en un mercado de alternativas no solo partidarias, sino también extrapartidarias» (Barrenechea, 2014: 24), como universidades-empresa, Organizaciones No Gubernamentales o del tercer sector.

Las instituciones públicas que sostienen la permanencia de la democracia representativa no son autorreferentes, es decir, su capacidad de acción no es endógena, por el contrario, son transformadas por los agentes políticos - entre adultos y jóvenes-, ambos actores con cargos de representación política. Además, la legitimidad de las autoridades políticas está vinculada con sus propias expectativas respecto a la democracia en situaciones favorables y críticas. En la teoría se refiere a la dicotomía de los demócratas verdaderos contra los demócratas precarios (Dargent, 2019), allí la perspectiva liberal intenta definir a los verdaderos como «a los actores políticos que respetan las reglas básicas de la democracia, mientras que los precarios, por el contrario, subordinan las reglas y valores de la democracia a sus intereses» (p. 41).

La participación juvenil en espacios organizados de la sociedad civil y de la política institucional presenta características particulares. El 46,2\% de regidores provinciales indica haber participado en un partido político, mientras que los porcentajes para consejeros regionales y regidores distritales fueron de $29,4 \%$ y $29,1 \%$. Esto muestra que, lejos de considerar a las y los jóvenes como apáticos del sistema político, las trayectorias políticas se inscriben en lógicas de adherencia política y un nivel mínimo de militancia partidaria, sea por vocación política o por intereses en la competencia electoral. 
Otro de los colectivos con mayores porcentajes de participación son las asociaciones o agrupaciones juveniles, donde el 35,3\% de consejeros regionales afirma haber estado involucrado(a), lo mismo indica el 16,5\% de regidores distritales y el 9,6\% de regidores provinciales. Estas asociaciones y agrupaciones juveniles se caracterizan por tener un fuerte componente territorial que permite definir sus identidades, de la misma forma presentan una estructura organizacional horizontal, flexible y adaptable a los cambios del entorno, donde sus integrantes participan poniendo en práctica valores como la autogestión, cooperación, voluntariado, asambleísmo y pluralismo.

Por el contrario, también existen espacios de organización que tienen menores porcentajes de participación. Respecto a los cargos políticos, se tiene que solo el 5,9\% de consejeros regionales indica haber participado en algún grupo religioso que podría ser a nivel parroquial-local o metropolitano; el 2,6\% de regidores distritales ha tenido participación en alguna agrupación de otro tipo que no necesariamente presenta un componente juvenil, además la poca participación en estas agrupaciones se debe a factores como su sostenibilidad y duración en el tiempo, participación concreta de la o el joven en dicha agrupación o colaboraciones indirectas; mientras que apenas el $0,9 \%$ de regidores provinciales ha participado en alguna Organización No Gubernamental (ONG), entidades no lucrativas que surgen generalmente por medio de financiamiento externo para la ejecución de proyectos y programas específicos que produzcan cambios en el entorno (ver gráfico 5). 


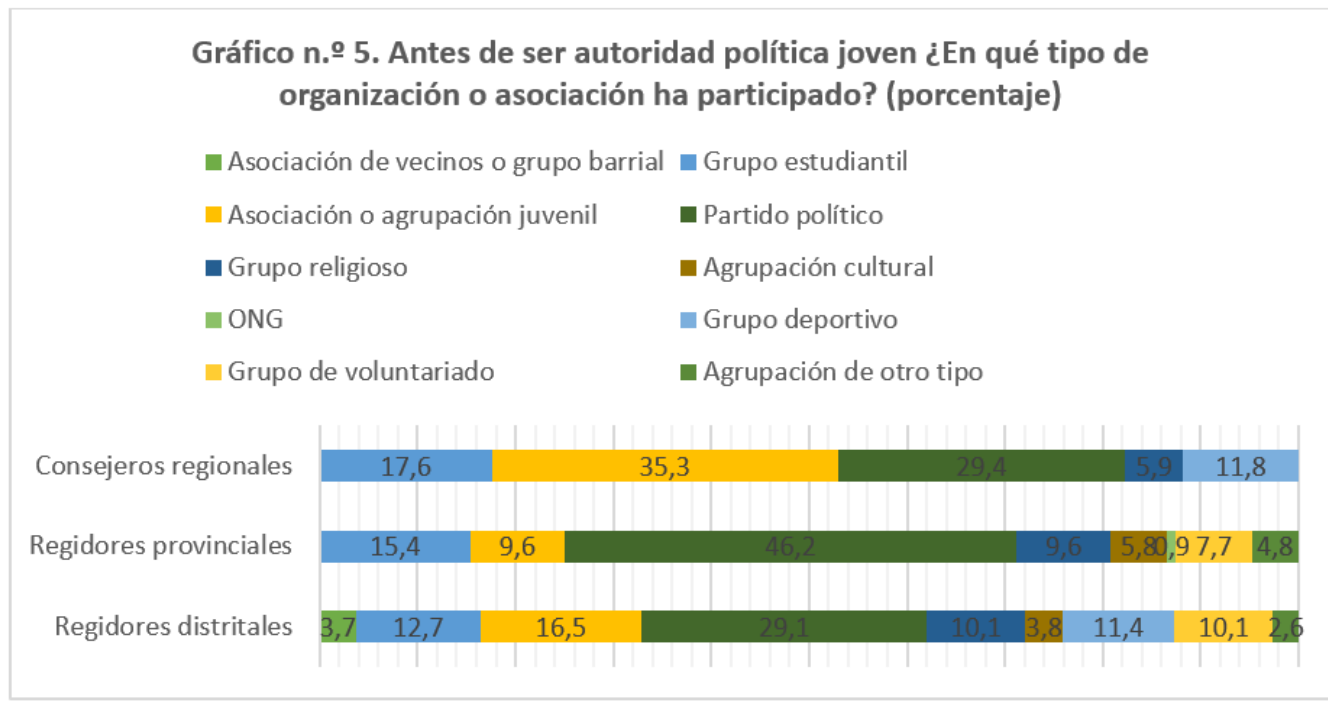

Fuente: Elaboración propia, sobre la base de encuesta a Autoridades Políticas Jóvenes 2015.

El estado de participación en asociaciones u organizaciones juveniles o en espacios organizados intergeneracionales (con presencia de personas adultas y jóvenes) presenta variaciones; las autoridades políticas jóvenes indican que han participado en estos espacios organizados como dirigente/representante, miembro activo sin cargo e incluso no teniendo participación en espacios organizados. El 41,7\% de consejeros regionales ha sido dirigente $\mathrm{y} / \mathrm{o}$ representante de su asociación u organización, mientras que el 33,3\% ha sido miembro activo(a), pero sin ocupar algún cargo. Por otra parte, el 28,6\% de regidores provinciales indica no haber participado en algún espacio organizado, mientras que el $26,5 \%$ ha sido miembro activo(a) sin cargo. Respecto a los regidores distritales, un mayoritario $45 \%$ menciona no haber participado en espacios organizados, mientras que el $22,9 \%$ opina que ha participado como miembro activo sin cargo.

Se puede notar que los consejeros regionales tienen mayor experiencia en dirigir o liderar una asociación u organización de la sociedad civil sea juvenil o intergeneracional, lo que les ha brindado experiencia para sus trayectorias en la competencia política. Esta legitimidad desarrollada como dirigente y 
representante permite acceder a redes de contacto a nivel regional que los vincule con movimientos políticos regionales expectantes de acceso al poder. Por otro lado, las autoridades políticas jóvenes provinciales y distritales muestran mayores porcentajes de no participación en los espacios organizados de la sociedad civil, lo que implica que sus trayectos de organización colectiva se sustentan en otras dinámicas de participación (ver gráfico 6).

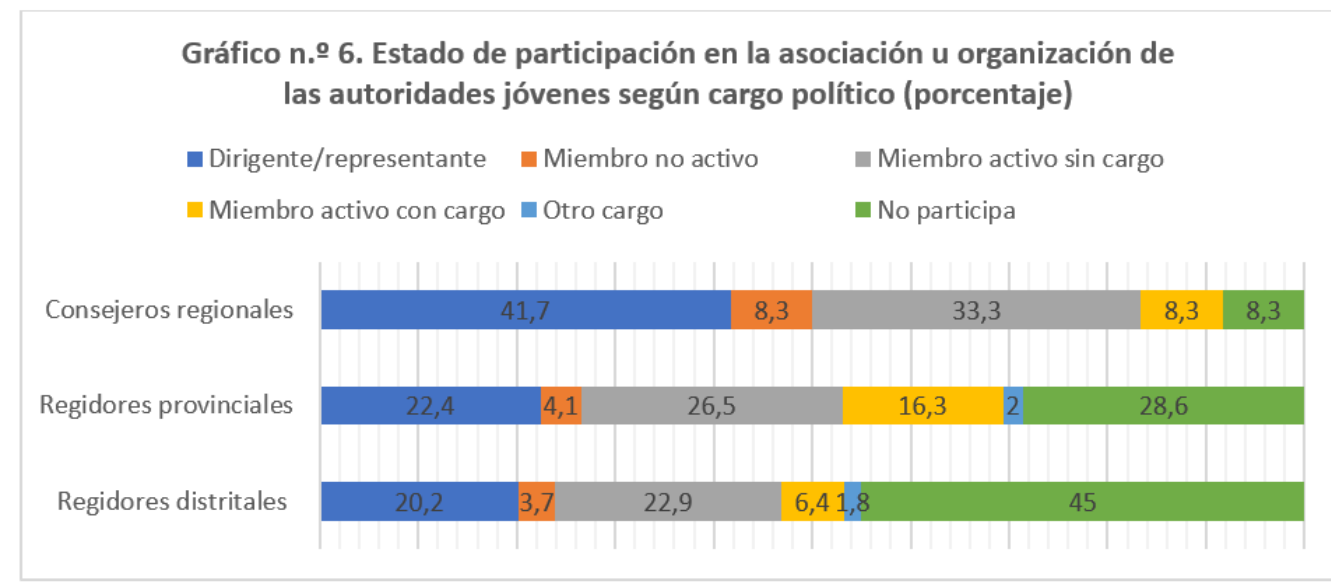

Fuente: Elaboración propia, sobre la base de encuesta a Autoridades Políticas Jóvenes 2015.

En lo que respecta a la trayectoria política según cargo de autoridad, el $58,3 \%$ de consejeros regionales expresa haber iniciado su trayectoria en la universidad, mientras que el 16,7\% menciona haberla iniciado tanto en la escuela como en el último proceso electoral (ambas categorías con ese porcentaje de forma individual). Por otra parte, el 29,8\% de regidores provinciales indica haber iniciado su trayectoria política en la universidad y el $25,5 \%$ en la escuela. Sin embargo, para la representación política local la opinión varía, puesto que para el 39,9\% de regidores distritales el inicio en actividad política se dio en el último proceso electoral, y el 19,3\% la inició en la escuela. 
Entonces, en promedio (porcentual), tanto la universidad como el último proceso electoral se constituyen en los principales espacios donde las autoridades políticas jóvenes iniciaron su trayectoria política. Esto tiene algunas implicancias, como el hecho de que dichas trayectorias son procesos simultáneos y en construcción, porque la participación en espacios estudiantiles universitarios no limita tener incidencia y participación en otros espacios como los partidos políticos, el barrio, vecindario o en el propio centro de trabajo. No obstante, dependerá de las dinámicas políticas que se manejen en cada espacio específico; además, estas trayectorias se encuentran en permanente construcción de lo político, las y los jóvenes adquieren experiencia en las correlaciones de poder dentro de los espacios estudiantiles y en la relación con las autoridades universitarias. El acceso a redes de contacto y las articulaciones con movimientos estudiantiles y de representación gremial son insumos para la formación de un perfil político y organizacional en las y los jóvenes.

El inicio de la trayectoria política en el último proceso electoral indica que la dinámica de inserción a la política institucional se asocia con el acceso al cargo de representación logrado por la competencia electoral. Las autoridades jóvenes ponen en debate el rol de los partidos políticos como espacios que profesionalizan la política y que adhieren un conjunto de valores, compromisos y fidelidad a la ideología de una organización partidaria. De hecho, según los resultados de la encuesta, en promedio solo el 14,3\% de autoridades políticas jóvenes indica que han sido los partidos políticos los espacios donde han iniciado su trayectoria política.

Esto pone en evidencia que las organizaciones partidarias no tienen la hegemonía ni la exclusividad como espacios para el ejercicio de prácticas políticas ni para la formación del perfil organizacional de las y los jóvenes, pues existe una oferta heterogénea de espacios organizados donde dichas experiencias, vivencias y significados se desenvuelven. Finalmente, en promedio, el 5,4\% de autoridades políticas jóvenes señala al contexto laboral como el espacio de inicio 
para la trayectoria política $(6,4 \%$ son regidores distritales y $4,3 \%$ son regidores provinciales).

Las y los jóvenes comienzan a resignificar y transformar sus dinámicas de participación en el sistema político, con nuevas propuestas y plataformas reivindicativas para ser visibilizadas por las agrupaciones políticas tradicionales, y es que dada la crisis de representación de las organizaciones políticas en el Perú, los denominados partidos políticos tradicionales o de masas ya no están en la capacidad de brindar una atractiva oferta política con propuestas programáticas, planes de gobierno y principios ideológicos a sus electores. Estos partidos se han convertido en elementos del mercado político como «agentes maximizadores de votos» (Rodríguez, 2009: 119) (ver gráfico 7).

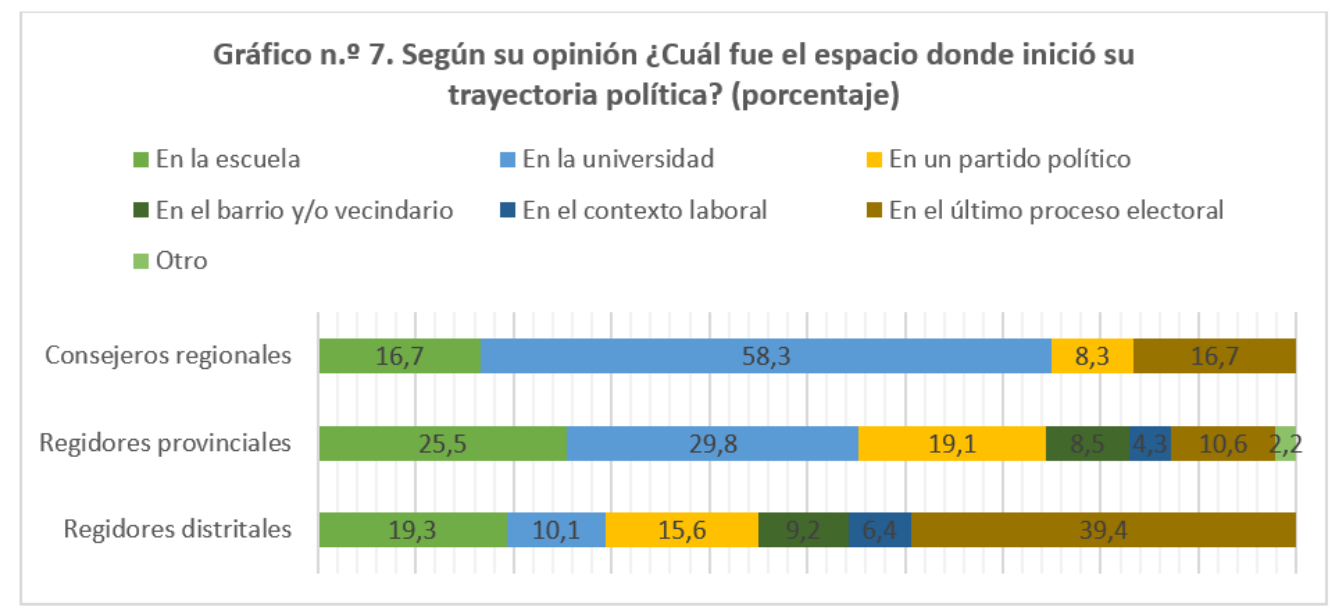

Fuente: Elaboración propia, sobre la base de encuesta a Autoridades Políticas Jóvenes 2015. 


\section{PERCEPCIONES SOBRE LA DEMOCRACIA Y LA} POLÍTICA

Las autoridades políticas jóvenes tienen distintas definiciones y opiniones en torno a la democracia como sistema de gobierno, pero también como forma de vida y de relación con otras personas. Por cargo políticos se tienen por lo menos cuatro bloques de opiniones y percepciones sobre la democracia, en el primero se la asocia con la realización de elecciones periódicas, limpias y transparentes, donde el $36,7 \%$ de regidores provinciales y el $28,8 \%$ de regidores distritales tienen esa percepción. Esta es una visión procedimental de la democracia y que se relaciona exclusivamente con la elección y el voto hacia candidatos políticos en la competencia electoral.

El segundo bloque vincula democracia con libertad de expresar libremente las ideas, pues tanto el 32,4\% de regidores distritales y el $28,6 \%$ de regidores provinciales tienen esa percepción. Esta mirada a la democracia se sustenta como derecho de expresión más amplia que el mero acto de ejercer el voto electoral o sufragio hacia candidatos políticos. Dicho ejercicio de la democracia como derecho no se limita a la estructura formal de la política, sino que implica una acción comunicativa para establecer el diálogo y construir el debate sobre lo público.

Un tercer bloque considera a la democracia como respeto de los derechos de todas las personas, donde el $41,7 \%$ de consejeros regionales y el $19,8 \%$ de regidores distritales tienen esa percepción; aquí la democracia se asocia a la propia condición humana de las personas como sujetos de derecho y ciudadanos(as) sociales y políticos. Estos son actores trascendentales en la acción del Estado para que se incorporen a los procesos de desarrollo, entonces el respeto va más allá de lo que está escrito en la legislación. Si bien las leyes son importantes, no son suficientes para las prácticas de reconocimiento hacia el otro, con diversas opiniones y características como ciudadano(a). 
Un cuarto bloque asocia a la democracia como la participación de la gente en los asuntos públicos, donde el $33,3 \%$ de consejeros regionales y el $18,4 \%$ de regidores provinciales opinan ello. En este bloque ya no basta el pleno reconocimiento de los derechos, sino que se añade la participación como elemento para la transformación del entorno y la socialización del poder en el ámbito público, no solo en la institucionalidad formal de la política (sistema de partidos políticos, elecciones para cargos y representantes, burocracia local), también como recurso deliberativo para poner en tensión las relaciones de poder existentes.

En promedio, solo el 2,5\% de autoridades políticas jóvenes considera a los partidos políticos como agentes principales de la democracia; si bien es innegable su importancia como intermediarios entre las demandas de la sociedad y la oferta política del Estado, estos no son los únicos. Se trata de buscar una democracia participativa más que representativa, con la participación de movimientos sociales, organizaciones locales, asociaciones juveniles, entre otros actores de la vida democrática (ver gráfico 8).

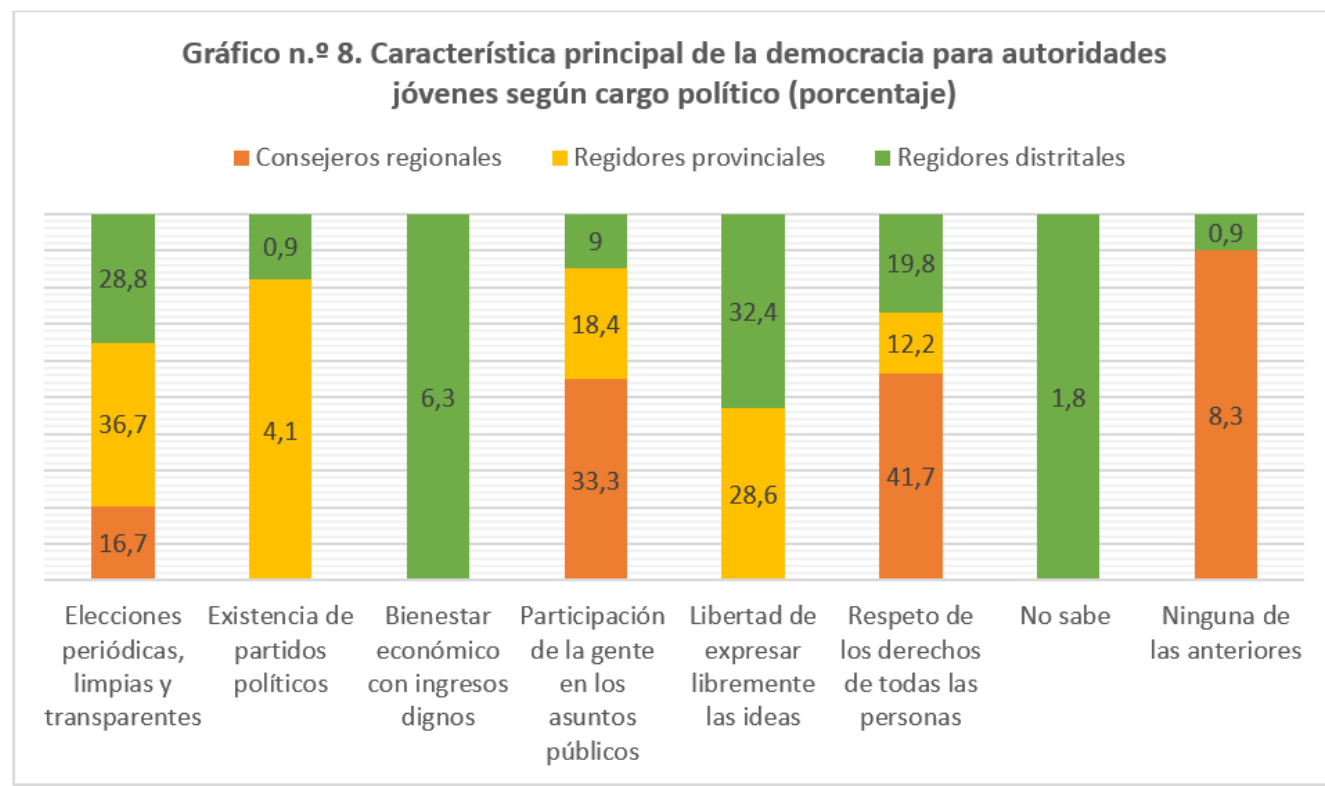

Fuente: Elaboración propia, sobre la base de encuesta a Autoridades Políticas Jóvenes 2015. 
La política desde la filosofía política está basada en «la dimensión de antagonismo que es constitutiva de las sociedades humanas» (Mouffe, 2007: 16). Aquí, lo que interesa no son tanto las prácticas ejercidas en las instituciones públicas para crear determinado orden, sino verlo como «un campo político atravesado por fuerzas» (Dussel, 2006: 16); a su vez requiere un conjunto de actores con voluntad que poseen poder, no se trata de sujetos individuales, sino de personas interrelacionadas que definen su relación con otros a través de estructuras de poder. Proponemos ver la política como un conjunto de componentes que involucra ciudadanía, Estado y comunidad política (Dussel, 2006). Todos ellos son agentes donde el poder no es exclusivo, sino que se ubica en la fluidez de las relaciones sociales que entablan entre ellos.

En lo que respecta al significado de la política como campo donde se construyen y disputan las relaciones de poder, existen opiniones diferentes. En promedio, el mayor porcentaje de autoridades políticas jóvenes $(67,6 \%)$ opina que la política significa la búsqueda del bien común; por cargo político los porcentajes de opinión están conformados por el 91,7\% de consejeros regionales, $63,3 \%$ de regidores provinciales y $47,7 \%$ de regidores distritales.

De esta forma, la política debe trascender los propios intereses individuales al menos en la teoría, el bien común remite a lo colectivo y al valor de lo público para generar procesos de desarrollo en la sociedad. La política representa una estrategia para alcanzar consensos y disputas de poder que satisfaga las demandas de sus propios representados(as). Además, son las autoridades políticas jóvenes del espacio regional quienes opinan a favor de este significado.

En promedio, el 24,2\% de autoridades políticas jóvenes piensa que la política significa diálogo y búsqueda de acuerdos entre grupos; por cargos, el $28 \%$ de regidores distritales y el $20,4 \%$ de regidores provinciales tienen esa opinión. Aquí se puede notar que son las autoridades políticas de los espacios 
subnacionales quienes tienen mayor simpatía por este significado. Esta concepción de la política se refiere a la generación de consensos entre fuerzas y/o posiciones diferentes, pero no necesariamente antagónicas ni con plataformas de acción irreconciliables, sino con una política más concreta y específica en el corto y mediano plazo para buscar el bien común en el largo plazo.

Los porcentajes más bajos definen a la política como búsqueda de control sobre personas y recursos ( $2 \%$ de regidores provinciales y $1,9 \%$ de regidores distritales) y como conflicto de intereses $(0,9 \%$ de regidores distritales). Estas definiciones ven a la política como un medio instrumental de intereses personales.

La política no es excluyente con el poder, de hecho, es parte de su propia constitución como estrategia para discutir los asuntos públicos. Una de las miradas clásicas fue la desarrollada por Max Weber (1967), para quien la política se refiere a «la influencia sobre la dirección de una asociación política, es decir, en nuestro tiempo de un Estado» (p. 82), y es que esta perspectiva sociológica define a la política como una aproximación de acceso al poder en las instituciones del Estado, entendida como «una relación de dominación de hombres sobre hombres, que se sostiene por medio de la violencia legítima» (p. 84). O sea, la política es una herramienta que busca tener influencia en la distribución del poder en el ámbito público, como un medio para conseguir otros fines o para poseer el estatus personal que esta confiere (ver gráfico 9). 


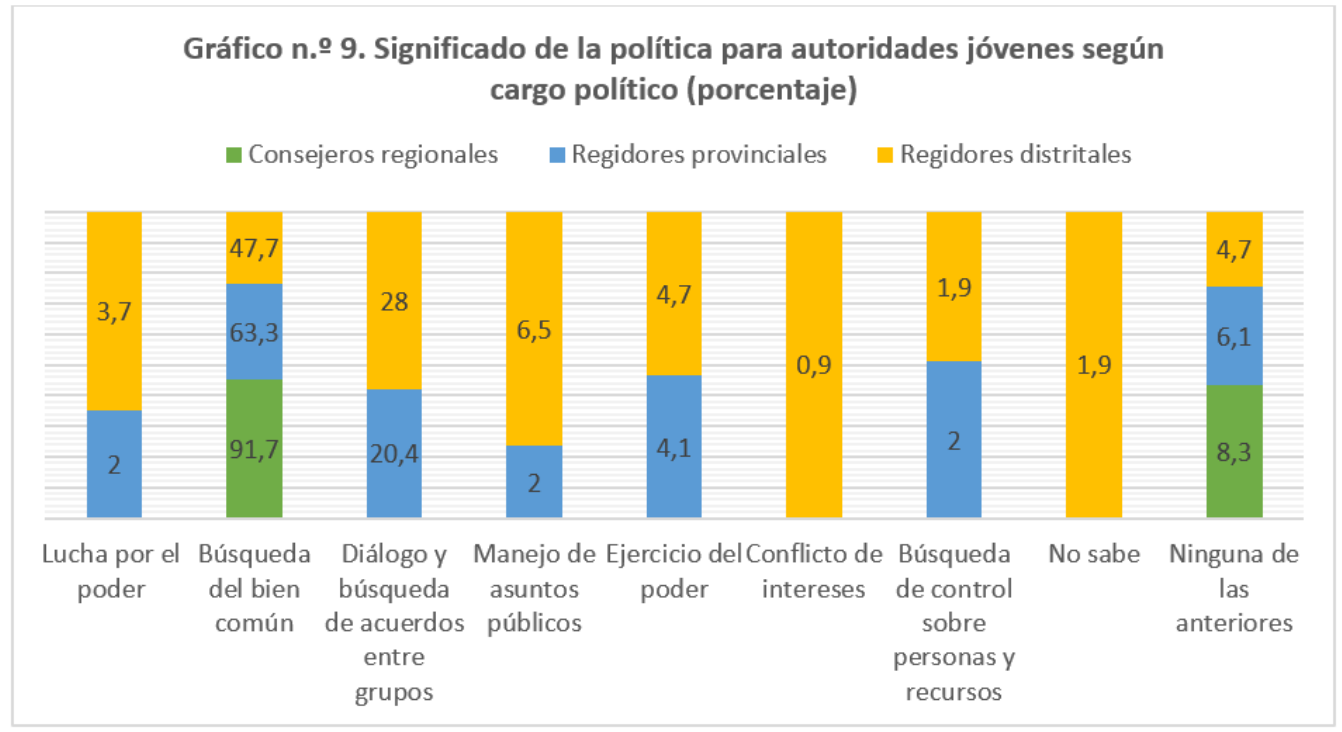

Fuente: Elaboración propia, sobre la base de encuesta a Autoridades Políticas Jóvenes 2015.

Respecto a la confianza que las autoridades políticas jóvenes tienen de las instituciones públicas, se puede apreciar que son las instituciones representativas nacionales quienes tienen menor porcentaje de legitimidad. El 81,4\% tiene ninguna o poca confianza en el Congreso de la República, el 80,8\% tiene ninguna o poca confianza en el Poder Judicial, mientras el 76,2\% expresa poca confianza en el Poder Ejecutivo. Precisamente, estas tres instituciones concentran los más altos niveles de desconfianza para las autoridades políticas jóvenes, instancias donde se diseñan, implementan y evalúan las políticas públicas al más alto nivel de gobierno.

Por otro lado, son las instituciones públicas más locales y cercanas en gobernanza local las que tienen los mayores porcentajes de confianza en la representatividad política, la democratización del poder y la deliberación de los asuntos públicos. El 44,8\% de autoridades políticas jóvenes confía lo suficiente en su municipalidad provincial y el 20,3\% confía bastante en ella. Mientras que el $39 \%$ confía lo suficiente en su municipalidad distrital y el $33,7 \%$ confía 
bastante (porcentaje mayor a la confianza depositada en la municipalidad provincial).

Llama la atención que la Iglesia como institución que promueve la religión (católica/cristiana) tiene altos porcentajes de confianza en las autoridades jóvenes, donde el 42,4\% indica confiar lo suficiente. Además, instituciones aparentemente «técnicas» y neutrales en las coyunturas políticas como El Jurado Nacional de Elecciones y la Oficina Nacional de Procesos Electorales presentan ninguna o poca confianza en las autoridades jóvenes, con $48,3 \%$ y $47,7 \%$, respectivamente (ver gráfico 10 ).

\section{GRÁFICO N.o 10. USTED COMO AUTORIDAD POLÍTICA JOVEN ¿CUÁNTO CONFÍA EN LAS SIGUIENTES INSTITUCIONES? (PORCENTAJE)}

\begin{tabular}{|c|c|c|}
\hline Su Municipalidad Distrital & 20,3 & 33,7 \\
\hline La Iglesia & 42,4 & 26,2 \\
\hline Su Municipalidad Provincial & 32,6 & 20,3 \\
\hline La Defensoría del Pueblo & 44,2 & 44,8 \\
\hline a Oficina Nacional de Procesos Electorales & 47,7 & 9,9 \\
\hline El Jurado Nacional de Elecciones & 48,3 & 11,6 \\
\hline Su Gobierno Regional & 51,7 & 41,9 \\
\hline Las Fuerzas Armadas & 64,5 & 26,2 \\
\hline La radio o televisión & 69,2 & 25 \\
\hline Los partidos políticos & 69,2 & $24,4 \quad 1,2$ \\
\hline La Policía Nacional del Perú & 69,8 & $24,4 \quad 1,7$ \\
\hline La prensa escrita & 72,1 & 23,3 \\
\hline El Poder Ejecutivo & 76,2 & $18 \quad 0,6$ \\
\hline El Poder Judicial & 80,8 & $14,50,6$ \\
\hline El Congreso de la República & 81,4 & $13,41,2$ \\
\hline
\end{tabular}

Fuente: Elaboración propia, sobre la base de encuesta a Autoridades Políticas Jóvenes 2015. 


\section{CONDICIÓN JUVENIL Y REPRESENTATIVIDAD}

La condición juvenil como etapa de vida diferenciada del mundo adultocéntrico implica un conjunto de características sociales, culturales, económicas y políticas específicas que reconocen la identidad de las y los jóvenes como actores en el presente. Sin embargo, la condición juvenil de las autoridades políticas se ubica en una trama de significados contradictorios dentro de las relaciones de poder frente a otros actores del mundo adulto, donde las autoridades jóvenes tienen que enfrentar etiquetas y estereotipos que ponen en duda sus capacidades profesionales. Para el 69,2\% de los encuestados(as), la condición juvenil ha facilitado el aporte de nuevas ideas, flexibilidad para adaptarse a los entornos de cambio, generar vínculos intergeneracionales, así como el uso de nuevas tecnologías de la información.

Resulta importante describir cuatro características transversales en materia de participación política juvenil descritas por Hopenhayn (1988). La primera es que permite obtener control sobre el propio proyecto de vida a través de un conjunto de intervenciones dentro del entorno personal y colectivo; la segunda característica se vincula con la distribución del poder y es la demanda por acceder a bienes y servicios logrados por la incidencia y la vigilancia ciudadana hacia sus autoridades políticas; la tercera tiene un interés por la integración a los procesos de desarrollo, esto es, suministrar herramientas de empoderamiento a las y los ciudadanos excluidos del sistema político y marginalizados de la estructura social. Y la cuarta característica resalta a los sujetos como individuos con derechos; aquí la participación busca realzar las capacidades individuales en materias de autonomía y reconocimiento a la identidad.

El 12,8\% indica que ser una autoridad política joven es una ventaja, el $10,5 \%$ expresa la necesidad de darse su lugar entre las personas mayores. Se resalta aquí un elemento diferenciador entre la política tradicional adulta y las y 
los jóvenes como actores políticos que buscan enfrentar dinámicas de exclusión, marginalidad y subordinación en las y los ciudadanos, el reto está en tejer vínculos intergeneracionales de manera equitativa con los demás grupos sociales. Además, el 2,9\% no contesta y el $0,6 \%$ considera que la condición juvenil no es una ventaja ni desventaja (ver gráfico 11).

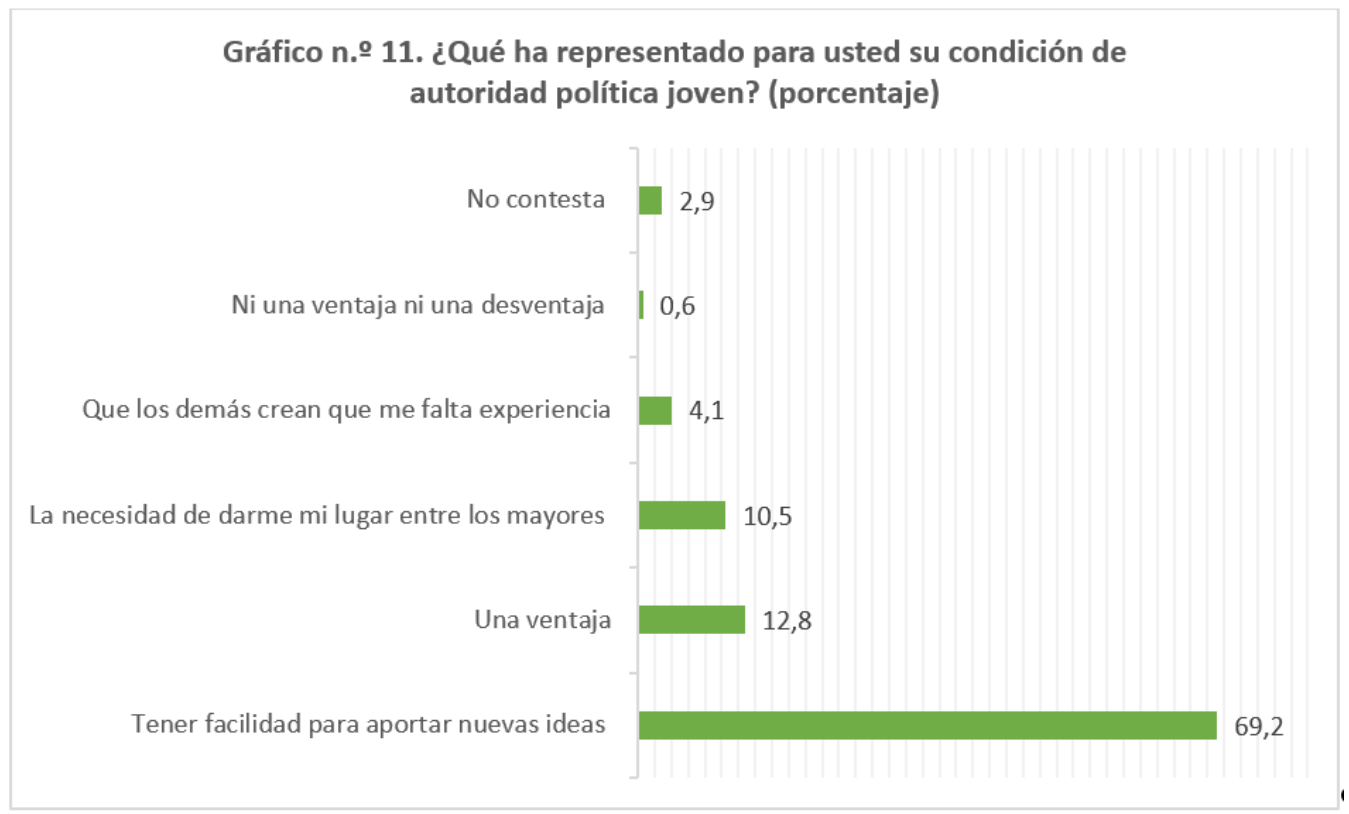

Fuente: Elaboración propia, sobre la base de encuesta a Autoridades Políticas Jóvenes 2015.

Las y los jóvenes son mucho más que un grupo poblacional definido por criterios de edad o personas en moratoria social con licencia para construir su identidad en el futuro. Además de ello y según sus propias condiciones de existencia, también son actores socioculturales con demandas específicas que velan por su presente y sus trayectorias futuras. El 39,5\% de encuestados(as) considera que ser un(a) líder para los demás debe ser la característica más importante de las autoridades políticas jóvenes, el 27,3\% opina que deben conocer los problemas que enfrentan las juventudes y el $16,3 \%$ cree que deben ser eficaces al solucionar los problemas. Con menores porcentajes se ubican: 
cumplir las promesas electorales $(3,5 \%)$, buena preparación académica $(2,9 \%)$ y la experiencia política $(0,6 \%)$.

Los mayores porcentajes se concentran en características como: liderazgo, conocimiento y eficiencia. Estas se encuentran ausentes en la política institucional y en el ejercicio de representación; el liderazgo implica un conjunto de habilidades personales que se articulan con las demandas de un colectivo y requieren elementos como la comunicación, asertividad, cooperación, trabajo en equipo y no necesariamente el ejercicio de la fuerza coercitiva para buscar obediencia, sumisión o legitimidad, este último concepto para poder respaldar el liderazgo juvenil ante la organización política, asociación o colectivo.

El conocimiento de los problemas juveniles implica tomar en cuenta las demandas heterogéneas de las y los jóvenes, así como una visión integral de sus condiciones de vida para generar plataformas programáticas en la representación política juvenil; la efectividad para la solución de estos problemas no solo involucra el conocimiento técnico, también el político, el poder incidir, cuestionar y reformar la estructura meritocrática en los puestos de representación del Estado. La experiencia política como característica menos valorada se vincula con los políticos y partidos tradicionales de la escena nacional, pues no es garantía que con dicha experiencia se tengan mejores niveles de calidad representativa en la vida política (ver gráfico 12 ). 


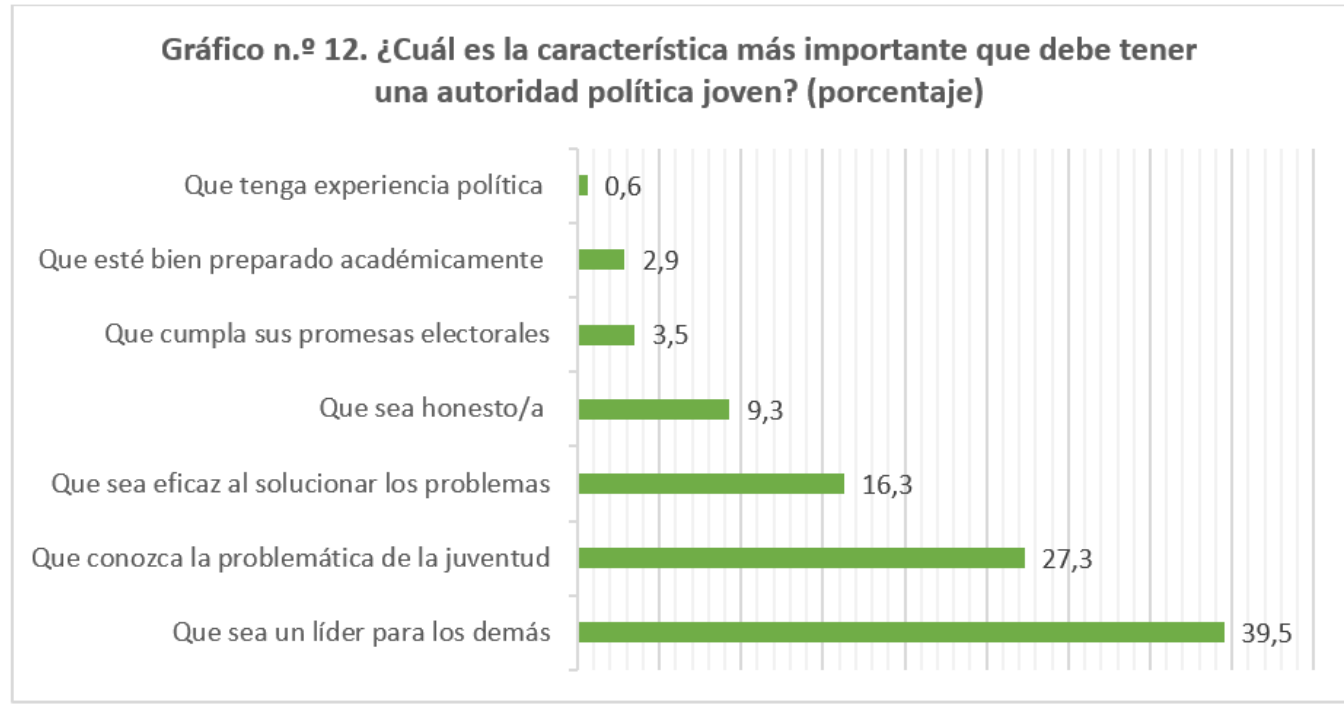

Fuente: Elaboración propia, sobre la base de encuesta a Autoridades Políticas Jóvenes 2015.

La participación juvenil en cargos políticos ha permitido transformar plataformas de propuestas en funciones de representación y acciones programáticas para la ejecución de políticas públicas. Las autoridades políticas jóvenes reconocen que sus nociones sobre el aumento o disminución de participación en estos espacios políticos de representación se basan en la propia experiencia personal de intervención, así como de las propias barreras en el acceso a las organizaciones políticas.

Precisamente la participación juvenil se convierte en un importante instrumento y derecho para involucrarse en los procesos de desarrollo y en la influencia para la distribución de poder dentro del Estado, en un contexto donde los partidos políticos peruanos tienen vínculos fragmentados con la ciudadanía y una legitimidad desgastada por las relaciones clientelares y corruptas establecidas con grupos de interés que se ubican en las cúpulas de los partidos políticos y en los gremios empresariales. Participar fuera como dentro del Estado implica una forma de aproximarnos y conocer la realidad social, permite que las 
y los jóvenes se interpelen a sí mismos y a las estrategias que implementan para articular sus propios objetivos de la vida cotidiana.

Las nociones que se tienen de la participación de jóvenes como congresistas nacionales son variadas; para el 42,5\% de encuestados(as) la participación dentro de esos cargos sigue igual, el 22,5\% indica que no existe participación y el 10,6\% expresa que a través de los ciclos de gobierno la participación juvenil como congresista nacional ha disminuido. Respecto a la elección como presidente regional joven, el 43,5\% tiene la noción de aumento, mientras el 40,4\% indica que la participación juvenil en ese cargo político sigue igual.

En torno a los consejeros regionales jóvenes, el 55,2\% opina que la participación en esos cargos ha aumentado, mientras el 48,8\% cree que la participación como alcaldes distritales jóvenes también ha tenido un aumento. Finalmente, el 49,7\% indica que la participación de jóvenes como alcaldes provinciales sigue igual. A nivel general se puede indicar que las opiniones mayoritarias se concentran entre «ha aumentado/sigue igual»; sin embargo, una instancia de representación legislativa a nivel nacional como el Congreso de la República es percibida como la institución de menor participación juvenil, caso contrario sucede con instancias de representación política más locales como las alcaldías distritales y las alcaldías provinciales, que son mejor valoradas.

Esto puede contextualizarse y sustentarse con la crisis de legitimidad que tiene el Estado como aparato de representación política de un conjunto de actores institucionales, formales y de la sociedad civil, tales como los partidos políticos. Por otro lado, la escasa legitimidad y credibilidad que tienen las instituciones políticas afectadas por altos niveles de corrupción y clientelismo origina que las trayectorias y carreras políticas juveniles enfrenten dificultades, desafíos y barreras (condición de edad, socioeconómica, generacional, política) que poco o 
nada incentivan la participación protagónica en la vida política del país (ver gráfico 13).

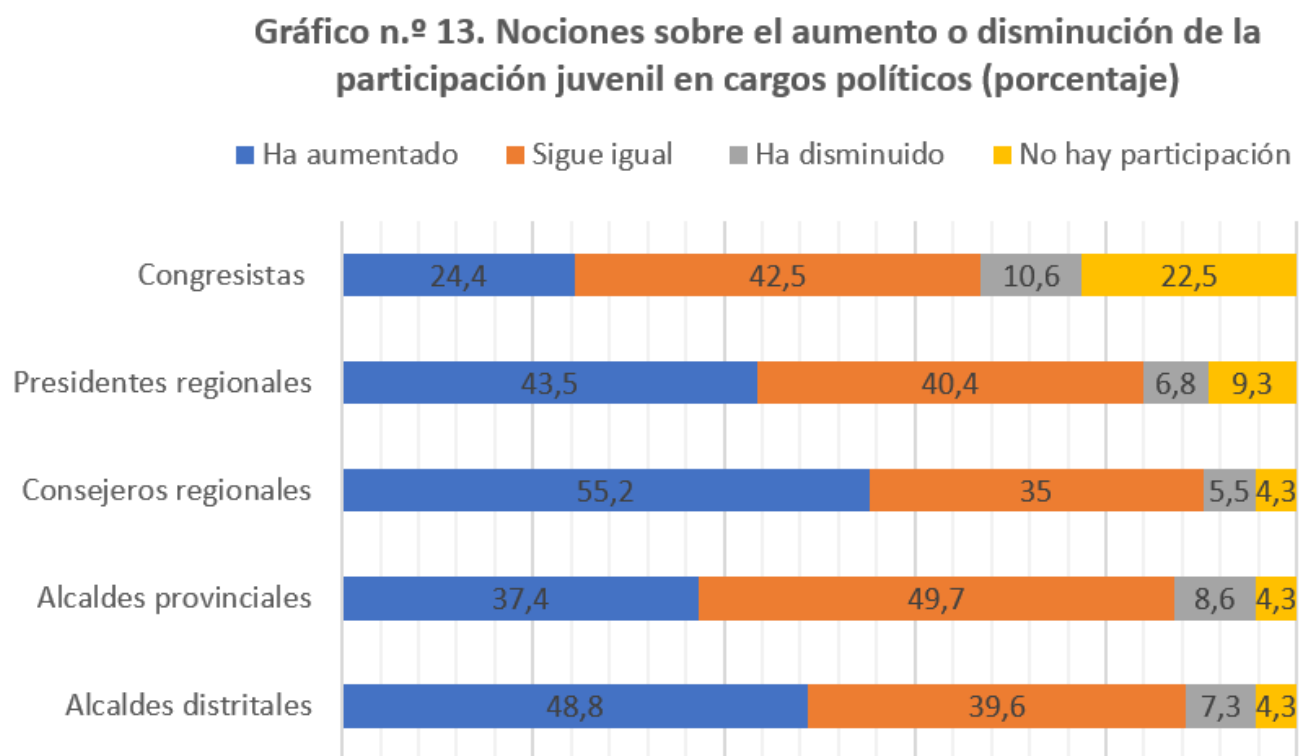

Fuente: Elaboración propia, sobre la base de encuesta a Autoridades Políticas Jóvenes 2015.

Las autoridades políticas jóvenes consideran que existen varios problemas estructurales que afectan la vida cotidiana de las y los jóvenes. El $59,9 \%$ considera como principal problema la limitada oferta laboral o el difícil acceso al trabajo, desde los conocimientos profesionales, para acceder al mercado de trabajo, como la falta de redes de contactos, escasa experiencia laboral, débiles escalas meritocráticos para el acceso a puestos laborales específicos y competentes. Incluso un conjunto de barreras intergeneracionales, donde suele asociarse la menor experiencia laboral con juventud, asociación propia del mundo adultocéntrico como forma de conocimiento hegemónico que considera a la juventud como etapa de transición al mundo adulto para cumplir los roles de reproducción social.

El segundo y tercer problema identificados fueron la delincuencia y pandillaje $(43,6 \%)$ y el consumo excesivo de alcohol y drogas $(35,5 \%)$, 
respectivamente, y es que desde el mundo adultocéntrico e incluso el Estado, se ha tomado a la juventud como un estado en constante riesgo que necesita adaptarse a los roles esperados por la sociedad adulta e integrarse a las dinámicas de reproducción social y a lo normativo. La preocupación por fenómenos como la delincuencia, la criminalidad juvenil, el pandillaje y el consumo de drogas se asocian con aquella cultura de la desviación, y se cae en conclusiones anticipadas que las y los jóvenes transgreden lo socialmente establecido y lo reproducido por el orden normativo del mundo adulto.

Existen otros problemas que afectan a los grupos juveniles según las autoridades políticas; en menor porcentaje están las dificultades para acceder a servicios de salud $(0,6 \%)$, trastornos de la alimentación y la imagen $(1,2 \%)$ y problemas de falta de vivienda $(1,7 \%)$.

Alayza (2006) define a la participación juvenil como «un sistema de valores que organiza la práctica y promueve la autonomía personal y la identidad» (p. 185), y es que de hecho participar en los asuntos de la vida pública implica reflexividad en las identidades juveniles, es un trayecto de autoreconocimiento y de conocimiento hacia los demás. La participación juvenil prioriza acciones inmediatas, orientadas a razones prácticas y del aquí y el ahora (Balardini, 2005), lejos de los horizontes difusos y difíciles de alcanzar en el largo plazo. Por otro lado, también se resalta el ejercicio de la individualidad cuando se participa, sea en organizaciones juveniles o dentro de los partidos políticos, y es que las y los jóvenes ya no adhieren necesariamente a colectivos masificados que eliminan la dimensión personal, por el contrario, buscan la participación individual en espacios horizontales como mesas de trabajo, redes, colectivos juveniles que garanticen prácticas deliberativas, lejos de las estructuras jerárquicas y verticales (ver gráfico 14). 


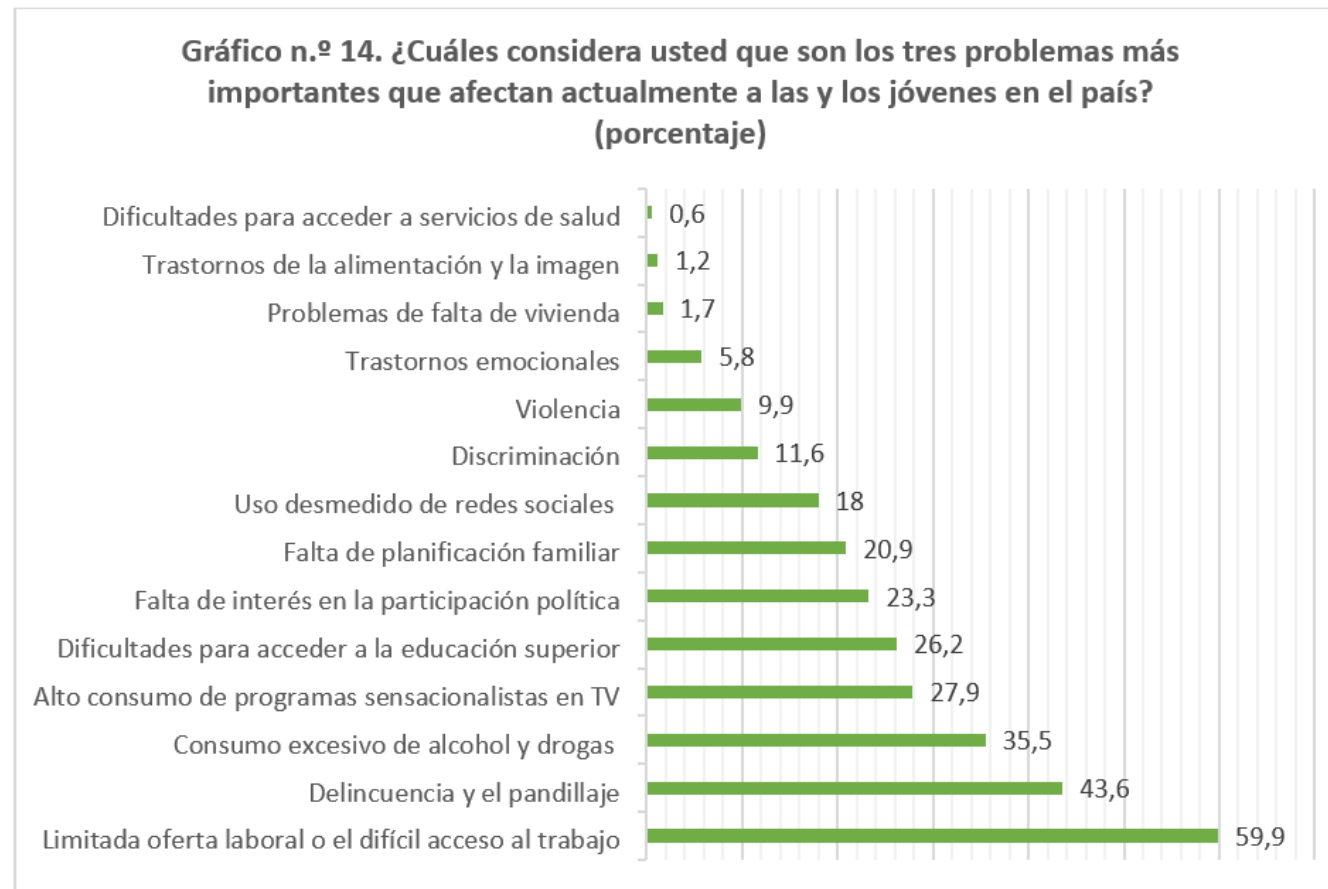

Fuente: Elaboración propia, sobre la base de encuesta a Autoridades Políticas Jóvenes 2015.

Tomando en cuenta la dimensión territorial y sus propias percepciones sobre las y los jóvenes organizados, casi el 80,2\% de las autoridades jóvenes encuestadas afirma que las y los jóvenes se encuentran por lo menos con algún nivel de organización colectiva básica dentro de sus regiones y/o localidades. De estos, el 27,3\% expresa que las y los jóvenes se organizan a veces por temas de coyuntura, como pueden ser manifestaciones y movilizaciones que buscan procesos de democratización nacional y disputas políticas frente al Estado.

El 25\% expresa que las y los jóvenes están débilmente organizados(as) y el 22,1\% describe que están organizados(as) pero sin mucha presencia pública, esto se vincula con la asociación específica y por objetivos concretos que las juventudes construyen en la vida pública para luego desvanecerse. Muchas de estas organizaciones juveniles están tuteladas por adultos, lo que limita su 
autonomía, sumada la informalidad existente en muchas de ellas y la falta de articulación con proyectos y programas juveniles (ver gráfico 15).

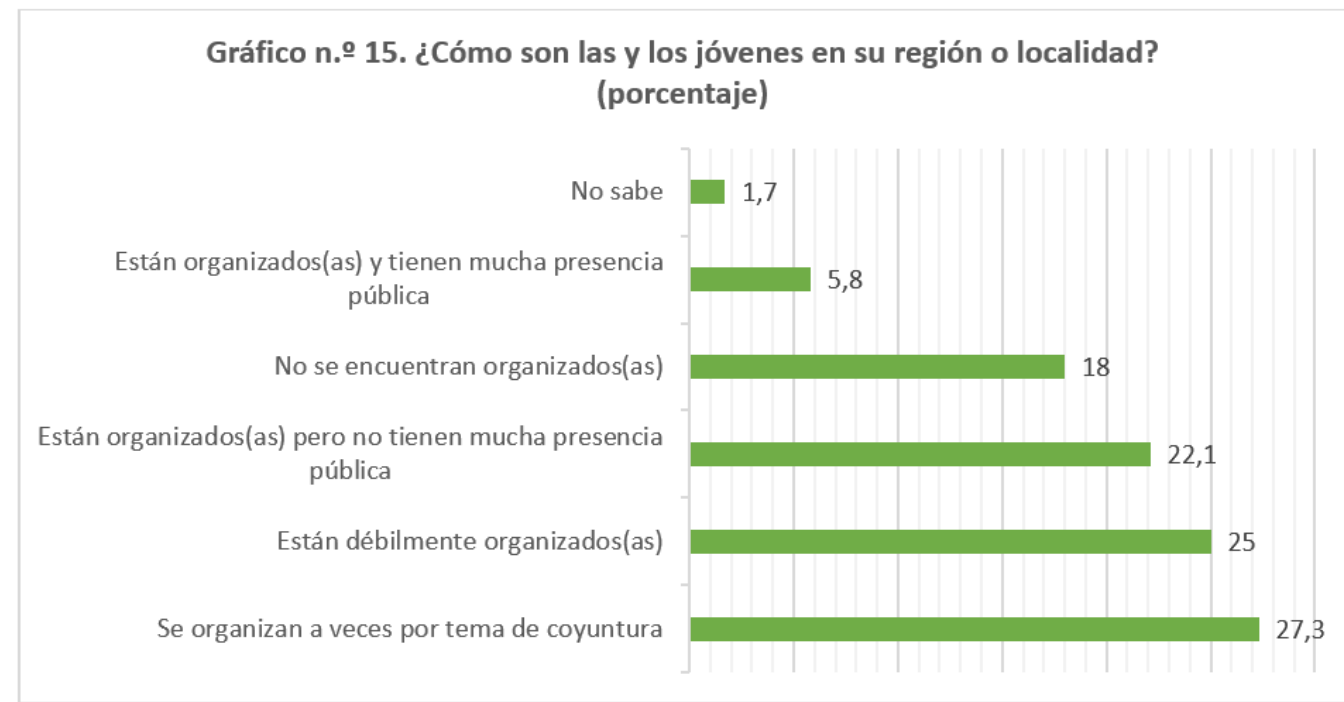

Fuente: Elaboración propia, sobre la base de encuesta a Autoridades Políticas Jóvenes 2015.

\section{Conclusiones}

Las percepciones y sentidos que las autoridades políticas jóvenes otorgan a los componentes de la política institucional tienen que ser comprendidos desde enfoques epistemológicos de las juventudes. Es decir, la producción de significados de la política tiene que ver con la influencia de las instituciones sociales sobre la condición juvenil (Sepúlveda, 2013). Las instituciones de socialización como la familia, la escuela, la universidad, el centro laboral y los partidos políticos construyen una situación particular con las juventudes. Por un lado, son vínculos relacionales y de interacción entre jóvenes e instituciones y, por otra parte, existe una lectura y, en consecuencia, una práctica regulatoria de la institucionalidad pública y la política como campo de fuerza sobre las juventudes que delimitan la experiencia y significado de ser joven. Muchas 
veces, sin tomar en cuenta la condición juvenil autónoma de los sujetos que se movilizan entre la integración y la emancipación.

Las juventudes ejercen prácticas de participación ciudadana en la política institucional como mecanismos de inserción a las decisiones públicas, de hecho, no se trata de una participación política que establece dicotomías entre el Estado y la sociedad, por el contrario, se trata de relaciones socioestatales (Espinosa, 2009). Aquí las estructuras del Estado no solo designan tareas y labores a los órganos de gobierno en el sector público, también «establecen los espacios para el despliegue de procesos participativos orientados a intervenir o interpelar las decisiones políticas» (Espinosa, 2009: 104).

Bajo el modelo de una ciudadanía estándar que privilegia las transiciones y participaciones homogéneas de las juventudes en esferas fragmentadas como la política, no es posible hablar de una ciudadanía juvenil en la práctica. En las sociedades del riesgo donde los referentes identitarios y los soportes institucionales no brindan garantías de éxito ni entornos predecibles, las juventudes políticas y quienes ejercen cargos de representación se encuentran en una situación de incertidumbre, pues deben enfrentar contextos impredecibles e implementar estrategias de resiliencia dentro del campo de la política institucional.

Las autoridades políticas jóvenes, además de transitar por los itinerarios hacia la vida adulta e insertarse a la lógica de la educación y el empleo, construyen sus trayectorias en la dimensión política para incidir en el debate como ciudadanos presentes que colocan en la agenda pública y mediática un conjunto de demandas y que solo es «posible entenderlas si se parte del nuevo contexto de incertidumbre e individualización en el que los jóvenes llevan a cabo sus trayectorias vitales» (Benedicto, 2016: 932). Sin embargo, no podemos dejar de lado que las posiciones políticas que asumen las y los jóvenes vienen por la identificación de problemas y dilemas que los afectan directamente y se 
encuentran ubicados en relaciones de poder (Evans, 2021), finalmente esto termina orientando los valores, creencias y discursos de la acción política.

ENVIADO: 6 DE FEBRERO DE 2021

ACEPTADO: 7 DE JULIO DE 2021 


\section{BibLIOGRAFÍA}

AlayzA, A. (2006). Hijos de su tiempo: notas sobre jóvenes y participación política. Desco, Perú Hoy, (10), 159-195.

BALARDINI, S. (2005). ¿Qué hay de nuevo viejo? Una mirada sobre los cambios en la participación política juvenil. Nueva Sociedad, (200), 96-107.

BALdeÓn, E. (2015). Cuota Joven y Cuota de Género. En E. RodríGueZ y J. CORCUERA (eds.), Subjetividades diversas. Análisis de la situación política, social y económica de las juventudes peruanas (pp. 299-313). Lima: SENAJU.

BANAJI, S. (2008). The trouble with civic: a snapshot of young people's civic and political engagements in twentyfirst-century democracies. Journal of Youth Studies, 11(5), 543-560.

BarrenecheA, R. (2014). Becas, bases y votos. Alianza para el Progreso y la política subnacional en el Perú. Lima: IEP.

BENEDicto, J. (2013). The political cultures of young people: an uncertain and unstable combinatorial logic. Journal of Youth Studies, 16(6), 712-729.

. (2016). La ciudadanía juvenil: Un enfoque basado en las experiencias vitales de los jóvenes. Revista Latinoamericana de Ciencias Sociales, $\begin{array}{llll}\text { Niñez } & y & \text { Juventud, } & \text { 925-938. }\end{array}$ https://doi.org/10.11600/1692715x.14203210415

BERMÚDEZ, V. (2018). La paridad como medida necesaria para la participación política de las mujeres en condiciones de igualdad (tesis de posgrado). Pontificia Universidad Católica del Perú, Lima.

Bustos, P. (1997). Jóvenes: Reflexiones en torno al tema de la participación y la política. Última Década, 5(7), 89-114. https://ultimadecada.uchile.cl/index.php/UD/article/view/56230

Casal, J., Merino, R. y García, M. (2011). Pasado y futuro del estudio sobre la transición de los jóvenes. Papers, 96(4), 1139-1162. https://doi.org/10.5565/rev/papers/v96n4.167

CAstellanos, J. (2011). La condición juvenil: opciones metodológicas para la construcción de un objeto de conocimiento. En G. Muñoz González (ed.), Jóvenes, culturas y poderes (pp. 161-187). Bogotá: Siglo del Hombre Editores.

DARGENT, E. (2019). Demócratas precarios. Élites y debilidad democrática en el Perú y América Latina. Lima: IEP.

DÁviLA, O. (2004). Adolescencia y juventud: de las nociones a los abordajes. Última Década, (21), 83-104. 
DÁVILA, O. y GHIARDo, F. (2018). Trayectorias sociales como enfoque para analizar juventudes. Última Década, 26(50), 23-39.

DEGREGORI, C. (2014). La década de la antipolítica: auge y huida de Alberto Fujimori y Vladimiro Montesinos. Lima: IEP.

Dussel, E. (2006). 20 tesis de política. México, D. F.: Siglo Veintiuno Editores.

EDWARDS, K. (2007). From deficit to disenfranchisement: reframing youth electoral participation. Journal of Youth Studies, 10(5), 539-555.

ESPINOSA, M. (2009). La participación ciudadana como una relación socioestatal acotada por la concepción de democracia y ciudadanía. Andamios, $5(10)$, 71-109. http://www.scielo.org.mx/scielo.php?script=sci_arttext\&pid=S187000632009000100004

Evans, F. (2021). Innovadores del cambio: Vivencias y significados de participación organizada en las y los jóvenes del distrito de Mi Perú (tesis de pregrado). Universidad Nacional Mayor de San Marcos, Perú.

FeIXA, C. (1999). De jóvenes, bandas y tribus. Barcelona: Ariel.

FERNÁNDEZ, A. (2003). Cultura política y jóvenes en el umbral del nuevo milenio. México, D.F.: Instituto Mexicano de la Juventud.

FERnÁndez MALdonAdo, E. (2015). La rebelión de los pulpines. Lima: Otra Mirada.

GoicocheA, J. (2020). Reflexiones sobre «el problema de la mujer» en el Perú. Revista Argumentos, 1(1), 59-80. https://doi.org/10.46476/ra.vi1.21

Hopenhayn, M. (1988). La participación y sus motivos. Santiago de Chile. Recuperado de: https://www.academia.edu/11397202/_LA_PARTICIPACI\%C3\%93N_ Y_SUS_MOTIVOS_.

JuRANDO NACIONAL DE EleCCIONES (JNE) (2015). Notas de prensa. Lima: JNE. Recuperado de: http://portal.jne.gob.pe/prensaypublicaciones/default.aspx del 01/01/15.

KIMBERLEE, R. (2002). Why dont British young people vote at general elections? Journal of Youth Studies, 5(1), 85-98.

Levitsky, S. y Zavaleta, M. (2019). ¿Por qué no hay partidos políticos en el Perú? Lima: Planeta.

LYNCH, N. (1999). Una tragedia sin héroes. La derrota de los partidos y el origen de los independientes. Perú, 1980-1992. Lima: UNMSM.

Mouffe, C. (2007). En torno a lo político. Buenos Aires: Fondo de Cultura Económica. 
NureñA, C. (2015). Juventud y cultura política en el Perú: el caso de los estudiantes de la Universidad Nacional Mayor de San Marcos de Lima (tesis de maestría). Universidad Iberoamericana de la Ciudad de México.

Oficina NAcional de Procesos EleCtORAles (ONPE) (2008). Nuevos actores en el mapa político. La cuota de género y la cuota de jóvenes en las Elecciones Regionales y Municipales de 2006. Lima: ONPE.

Rodríguez, E. (ed.) (2013). Movimientos juveniles en América Latina: entre la tradición y la innovación. Lima: Secretaría Nacional de la Juventud y UNESCO.

RODRÍGUEZ, L. (2009). Entre los nuevos y los viejos caminos: la relación ciudadanos-sistema político. Andamios, 5(10), 111-138.

SeCRetaría NACIONAL DE LA JUVENTUd (SENAJU) (2015). Informe nacional de las juventudes en el Perú-2015. Lima: SENAJU.

SEPÚlvEDA, L. (2013). Juventud como transición: Elementos conceptuales y perspectivas de investigación en el tiempo actual. Última Década, 21(39), 11-39.

https://ultimadecada.uchile.cl/index.php/UD/article/view/56133/59345

SERNA, L. (1998). Globalización y participación juvenil. Jóvenes. Revista de estudios sobre juventud, 4(5).

Souto, S. (2007). Juventud, teoría e historia: la formación de un sujeto social y de un objeto de análisis. Historia Actual Online, (13), 171-192.

TANAKA, M. (1995). Jóvenes: actores sociales y cambio generacional. De la acción colectiva al protagonismo individual. En J. COTLER (ed.), Perú 1964-1994: economía, sociedad y política (pp. 149-165). Lima: IEP.

TERESHCHENKO, A. (2010). Ukrainian youth and civic engagement: unconventional participation in local spaces. Journal of Youth Studies, 13(5), 597-613.

Valenzuela, J. (2012). Sed de mal: feminicidio, jóvenes y exclusión social. México, D. F.: El Colegio de la Frontera Norte.

. (2005). El futuro ya fue. Juventud, educación y cultura. Anales de la educación común, 1(1-2), 28-71.

Weber, M. (1967). El político y el científico. Madrid: Alianza Editorial.

YÁÑEZ, A. (2001). Mujeres y política, el poder escurridizo. Las cuotas en los tres últimos procesos electorales. Lima: Movimiento Manuela Ramos. 